\title{
Modes of spontaneous chromosomal mutation and karyotype evolution in ants with reference to the minimum interaction hypothesis
}

\author{
Hirotami T. IMAI ${ }^{1)}$, Robert W. TAYLOR ${ }^{2)}$, Michael W. J. CROSLAND ${ }^{3)}$, \\ and Ross H. CROZIER ${ }^{3)}$ \\ 1) National Institute of Genetics, Mishima, Shizuoka-ken, 411 \\ 2) Division of Entomology, C.S.I.R.O., Canberra, A.C.T., 2601 Australia \\ 3) School of Biological Science, The University of New South Wales, \\ Kensington, N.S.W., 203s Australia
}

(Received December 2, 1987)

\begin{abstract}
Aspects of chromosomal mutation and karyotype evolution in ants are discussed with reference to recently accumulated karyological data, and to detailed karyotype analyses of several species or species complexes with low chromosome number and unusual chromosomal mutations (the complexes of Myrmecia pilosula (Smith) $(\mathrm{n}=1,5$ or 9 to 16); $M$. piliventris Smith $(\mathrm{n}=2,3-4,17$ or 32$)$, and Ponera scabra Wheeler ( $\mathrm{n}=3$ or $4,2 \mathrm{n}=7$ or 8$)$ ). Translocations and Robertsonian polymorphisms are confirmed to be non-randomly distributed among ants -the former are found at high frequencies in species with low chromosome numbers $(n \leq 12)$, while the latter predominate in those with high numbers (n $>12)$. This situation is consistent with the minimum interaction hypothesis of Imai et al. (1986), under which translocations are expected to occur most frequently in low-numbered karyotypes, and that the resulting genetic risks are minimized by increases in chromosome and/or arm numbers through centric fission and pericentric inversion. Centric fusion is considered to be a transient event in karyotype evolution, resulting from telomere instability in acrocentric chromosomes.
\end{abstract}

\section{INTRODUCTION}

About ten years ago, Imai et al. (1977) reported the non-random occurrence of spontaneous chromosomal mutations among Australian ants. Translocation polymorphisms were then shown to be represented preferentially in species with low chromosome numbers $(n \leq 12)$, while Robertsonian polymorphisms to predominate in those with higher numbers. The same phenomena were later observed in Indian ants (Imai et al., 1984) (Fig. 1). These non-random phenomena (especially that involving translocations) may appear paradoxical, because (1) in theory, the frequency of translocations should increase as chromosome numbers increase, and

1) Corresponding author. 


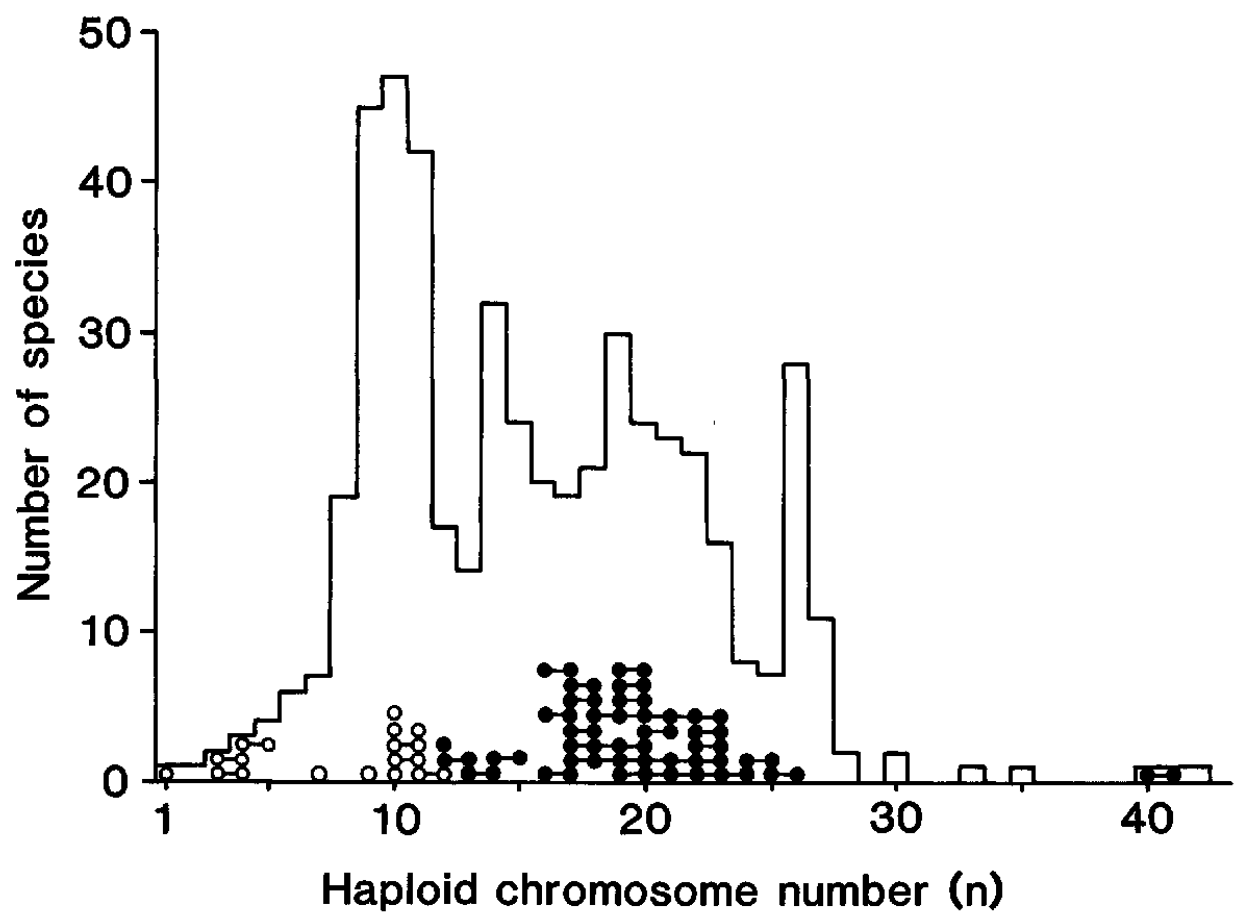

Fig. 1 Frequency distribution of haploid chromosome numbers in ants, showing the non-random distribution of translocation (open circles) and Robertsonian polymorphisms (solid circles). Chromosome numbers involved in the same polymorphic series are connected by short bars. For detailed data see Tables 4 and 5.

because (2) translocations are seldom found in natural populations, due presumably to the selective disadvantage of heterozygotes (Wright, 1941; White, 1973: 285; Lande, 1979). Imai et al. (1977) suggested that translocations likely arise at a constant rate in all species, but that karyological evidence of their presence is obscured in species with high chromosome numbers because of rapid karyotypic changes following Robertsonian rearrangements.

There is, however, an alternative interpretation: It assumes that the intrinsic rate of translocations in ant species with low chromosome numbers is indeed high, but that increase in chromosome number by Robertsonian rearrangement is evolutionarily advantageous, since it would minimize the genetic risks resulting from high translocation frequencies. This proposition formed the basis of the minimum interaction hypothesis (Imai et al. 1986 and Imai 1986), proposed as a global model for karyotype evolution in eukaryotes.

Here we present the available data concerning spontaneous chromosomal mutations in ants and discuss the evolutionary significance of the non-random distribution of translocations among these insects in the light of the minimum interaction hypothesis. 


\section{MATERIALS AND METHODS}

\section{1) Organisms}

The major nominal species considered here are Myrmecia pilosula (Smith), and $M$. piliventris Smith, representatives of the many 'Bulldog Ant' species of Australia. M. pilosula is commonly known in Australia as the 'Jack Jumper' because of the hopping behaviour of its workers. The material studied was collected in eastern New South Wales, Queensland and the Australian Capital Territory (Table 1), during the late spring and early summer of 1985, when advanced larvae and prepupae (pharate pupae) suitable for karyological processing were present in the nests. Myrmecia is the sole genus in the subfamily Myrmeciinae, which is considered to be primitive among ants (Taylor, 1978). The genus is generally fairly conserved morphologically among its species, especially within some of its component species groups (at least among the female castes), and this makes it difficult to detail the presence of sibling species in some groups. The total number of species in nature must well exceed 90 , the number currently recognized species, which share 140 available names (Taylor, 1987). In many cases specimens sorted to putative species in museum collections clearly represent complexes of closely similar biological species. The nominal species $M$. pilosula and $M$. pilliventris are excellent examples of this. We have adopted the procedures of Article 6(b) of the International Code of Zoological Nomenclature (Third Edition) (1985) in our use of these names. Either specific name cited in parenth-

Table 1. Localities and codes of ants used in this study

\begin{tabular}{|c|c|}
\hline $\begin{array}{l}\text { Species and } \\
\text { code(s) of colony } \\
\text { (HI85-) }\end{array}$ & Locality \\
\hline \multicolumn{2}{|c|}{ Myrmecia piliventris complex } \\
\hline 171,172 & $\begin{array}{l}\text { Lower eastern slopes of Black Mountain }\left(35^{\circ} 16^{\prime} \mathrm{S}, 149^{\circ} 06^{\prime} \mathrm{W}\right) \text {, Canberra, } \\
\text { A.C.T. at elevations of around } 560-600 \mathrm{~m} \text {. }\end{array}$ \\
\hline 188 & $\begin{array}{l}12 \mathrm{Km} \text { to the southeast, on Jerrabonberra Hill }\left(35^{\circ} 21^{\prime} \mathrm{S}, 149^{\circ} 14^{\prime} \mathrm{E}\right) \text { at ca. } 780 \mathrm{~m} \\
\text { elevation, near Queanbeyan, N.S.W. }\end{array}$ \\
\hline 210 & Australian National University campus (Canberra). \\
\hline 211,241 & $\begin{array}{l}8 \mathrm{Km} \text { east of Nelligen Creek Bridge, N.S.W. ( } 6 \mathrm{Km} \text { west of Nelligen }\left(35^{\circ} 39^{\prime} \mathrm{S} \text {, }\right. \\
\left.150^{\circ} 08^{\prime} \mathrm{E}\right) \text { ), at ca. } 120-140 \mathrm{~m} \text { elevation. }\end{array}$ \\
\hline 302 & $9.5 \mathrm{Km}$ west of Ravenshoe $\left(17^{\circ} 36^{\prime} \mathrm{S}, 145^{\circ} 29^{\prime} \mathrm{E}\right)$ in north eastern Queensland. \\
\hline \multicolumn{2}{|c|}{ Myrmecia (pilosula) complex } \\
\hline $\mathbf{n}=1$ & Tidbinbilla Nature Reserve $\left(35^{\circ} 28^{\prime} \mathrm{S}, 148^{\circ} 53^{\prime} \mathrm{W}\right)$, near Canberra, A.C.T. \\
\hline $\begin{array}{l}192-195,227 \\
228,233\end{array}$ & Ca. $4 \mathrm{Km}$ south of Mongarlowe $\left(35^{\circ} 25^{\prime} \mathrm{S}, 149^{\circ} 57^{\prime} \mathrm{E}\right)$, N.S.W. \\
\hline $\begin{array}{l}374,375,378 \\
379\end{array}$ & Piccadilly Circus $\left(35^{\circ} 22^{\prime} \mathrm{S}, 148^{\circ} 49^{\prime} \mathrm{E}\right)$, A.C.T. \\
\hline 376 & Condor Creek $\left(35^{\circ} 19^{\prime} \mathrm{S}, 148^{\circ} 50^{\prime} \mathrm{E}\right)$, A.C.T. \\
\hline Ponera scabra & Manazuru peninsula, Kanagawa-ken, (Japan). \\
\hline
\end{tabular}


esis refers to the complex of putative species centered on the 'good' species named $M$. pilosula or $M$. piliventris. The two central species are referred to conventionally (e.g., $M$. pilosula), and where appropriate the chromosome number of a particular chromosome morph is appended to the name of its complex (e.g., $M$. (piliventris) $2 n=34$ ). M. pilosula has not yet been taxonomically discriminated among the members of its complex discussed here, though we suppose that one of them will be 'true' pilosula. The names pilosula and (its present synomym) muginoda are the only ones known to be available to this complex. M. piliventris was discriminated among its relatives by Imai and Taylor (1986).

Despite being somewhat morphologically conservative, the speices of Myrmecia are very highly divergent chromosomally (Imai et al., 1977; Crosland and Crozier, 1986; Imai and Taylor, 1986). The range of known chromosome numbers $(n=1-$ 41 or $2 n=2-81$ ) exceeds that of any other genus of eukaryotes, and the maximum is exceeded in the Hymenoptera only by another, related, primitive Australian ant, Nothomyrmecia macrops Clark (Subfamily Nothomyrmeciinae) $(2 \mathrm{n} \approx 90$; Taylor, 1978). Members of the Myrmecia (pilosula) complex are characterized by complicated chromosome polymorphisms $(n=1,5$, or 9-16), and were considered to include at least three (not very) different morphotypes by Crosland et al. (1987). These probably represent sibling species, long suspected to be present in the pilosula group by taxonomists. There are likely to be several more, since $M$. (pilosula) is widespread, and not all available museum specimens can be sorted to the three morphotypes mentioned. Myrmecia (piliventris) is more clearly morphologically diverse, doubtless inclduing several sibling or near-sibling species, of which some probably have available specific names but have tended to be 'lumped' by identifying taxonomists. Samples of these ants have yielded chromosome numbers of $n=2,3,17$, and 32, and their morphology suggests that they are separate species. There might be some karyotypic homology between $M$. (pilosula) $n=1$, and (piliventris) $n=2$, or at least the relevant (pilosula) karyotype might have had an antecedent with a (piliventris) $n=2$-like karyotype, as suggested by Imai and Taylor (1986). The two species complexes are, however, quite distinct morphologically, and are usually placed by taxonomists in separate species groups of Myrmecia (e.g., Clark, 1951; Brown, 1953).

Voucher specimens are deposited in the Australian National Insect Collection (ANIC), CSIRO, Canberra. They bear code numbers prefixed 'HI85' ( $=\mathrm{H}$. Imai, 1985). Identifications are by R.W.T. The Japanese species Ponera scabra Wheeler (Ponerinae) was studied using material collected by Dr. M. Kubota and Dr. K. Masuko at Manazuru, Honshu, Japan, in 1986 and 1987. This species has a stable translocation polymorphism $(n=3,4$, and $2 n=7,8)$ (Imai and Kubota, 1972, and present data).

\section{2) Chromosome preparation}

Chromosome materials were prepared using an improved version of the air- 
drying technique developed progressively by Imai et al. (1977), and Imai et al. (1984a). This yields high-quality conventional metaphase figures and C-banded karyotypes, without subsequent treatment. The same procedures have been applied to other insects (e.g., Drosophila ananassae (Matsuda et al., 1983), and to the trematode platyhelminth Paragonimus ohirai (Hirai et al., 1981). A detailed description of the improved technique used in this study follow:

Chemicals: (1) Colchicine stock solution ( $0.1 \%$ solution: $1 \mathrm{mg}$ colchicine/ $1 \mathrm{ml}$ distilled water). (2) Hypotonic solution (1\% sodium citrate solution: $1 \mathrm{~g}$ trisodium citrate dihydrate/ $100 \mathrm{ml} \mathrm{d.w.).} \mathrm{(3)} \mathrm{Colchicine-hypotonic} \mathrm{solution}(0.005 \%$ colchicine: $0.5 \mathrm{ml}$ colchicine stock solution $\mathbf{9 . 5} \mathrm{ml}$ hypotonic solution; freshly prepared). (4) Fixative I (60\% 1:1 acetic-ethanol: glacial acetic acid $3 \mathrm{ml} /$ ethanol $(99.5 \%) 3 \mathrm{ml} /$ d.w. $4 \mathrm{ml}$; freshly prepared). (5) Fixative II (1:1 acetic-ethanol: glacial acetic acid $2 \mathrm{ml} /$ ethanol $(99.5 \%) 2 \mathrm{ml}$; freshly prepared). (6) Fixative III (glacial acetic acid).

Organs: (1) Cerebral ganglia of prepupae, taken at a stage just after defecation (i.e., deposition of the meconium), and while the first few body segments are swollen and transparent (Fig. 2b, 2d, 2e). (2) Testes from male pupae with the compound eyes pale red (Figs. 2c, 2f). (3) Ovaries from queen pupae, with the compound eyes deep red (for oogonial metaphases), or at a late pupal stage (for meiosis) (Figs 2c, 2g). The best stages for chromosome preparations, indicated above, are almost the same for all ants, but differ in other insects.
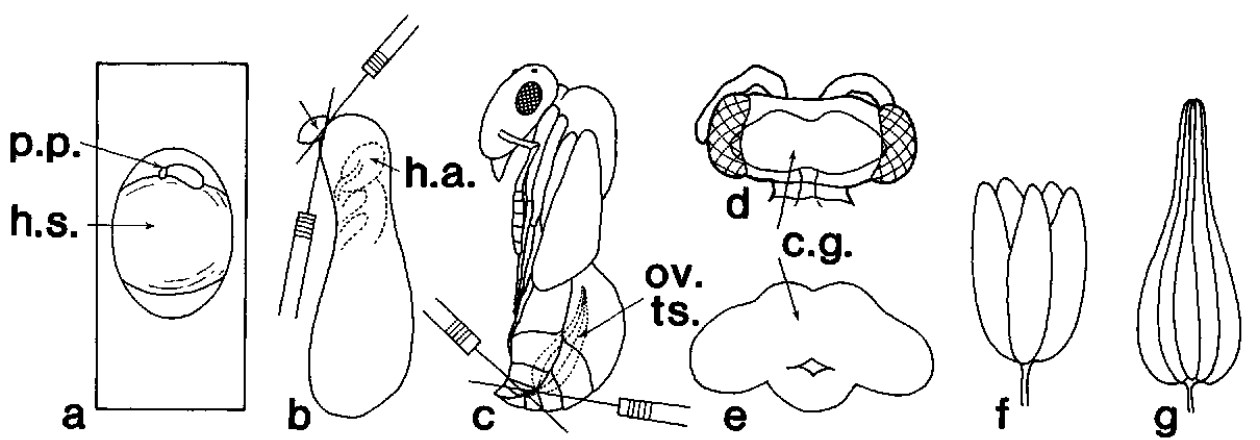

Fig. 2 Organs used for chromosome preparations in ants. (h.s. hypotonic solution; p.p.=prepupa; h.a. = head of adult; ov. =ovary; ts. =testis; c.g. =cerebral ganglion). For details see text.

Slide making: (1) Dissect out subject organs in colchicine-hypotonic solution on a cavity slide (Figs. 2a, 2b), using dissecting needles, removing as much as possible of the fat body, tracheae and epithelial membranes (for cerebral ganglia see Figs. 2d, 2e). (2) Transfer organs to fresh colchicine-hypotonic solution on another depression slide, using Pasteur pipette; leave for 20 mins (max. $1 \mathrm{hr}$ ) at room temperature. (3) Transfer material onto a pre-cleaned plain slide using 
Pasteur pipette (Fig. 3a). (4) Incline slide at $10-20^{\circ}$, to drain off most of the hypotonic solution (Fig. 3b), and draw off as much as possible of the drop around the organs, using a dissecting needle (Fig. 3c). (5) Incline slide at $10-20^{\circ}$; apply several drops of freshly prepared fixative I to the preparation and over the surface of the slide, except where it is being held (Fig. 3d). The fixative should flow over the preparation and drain off the end of the slide. (6) Remove remaining fixative from end of slide using filter paper (Fig. 3e). (7) Observe slide under stereomicroscope; and add two further drops of fixative I directly onto material (Fig. 3f). After 15-30 secs, macerate organs as quickly as possible using dissecting needles to spread cells and cell-mass outwards (Figs. 3g, 3h). Fixative I spreads outwards at first, and then retracts (Fig. 3i). (8) Just before this retraction add two drops of freshly prepared fixative II (Fig. 3j), so that fixative I
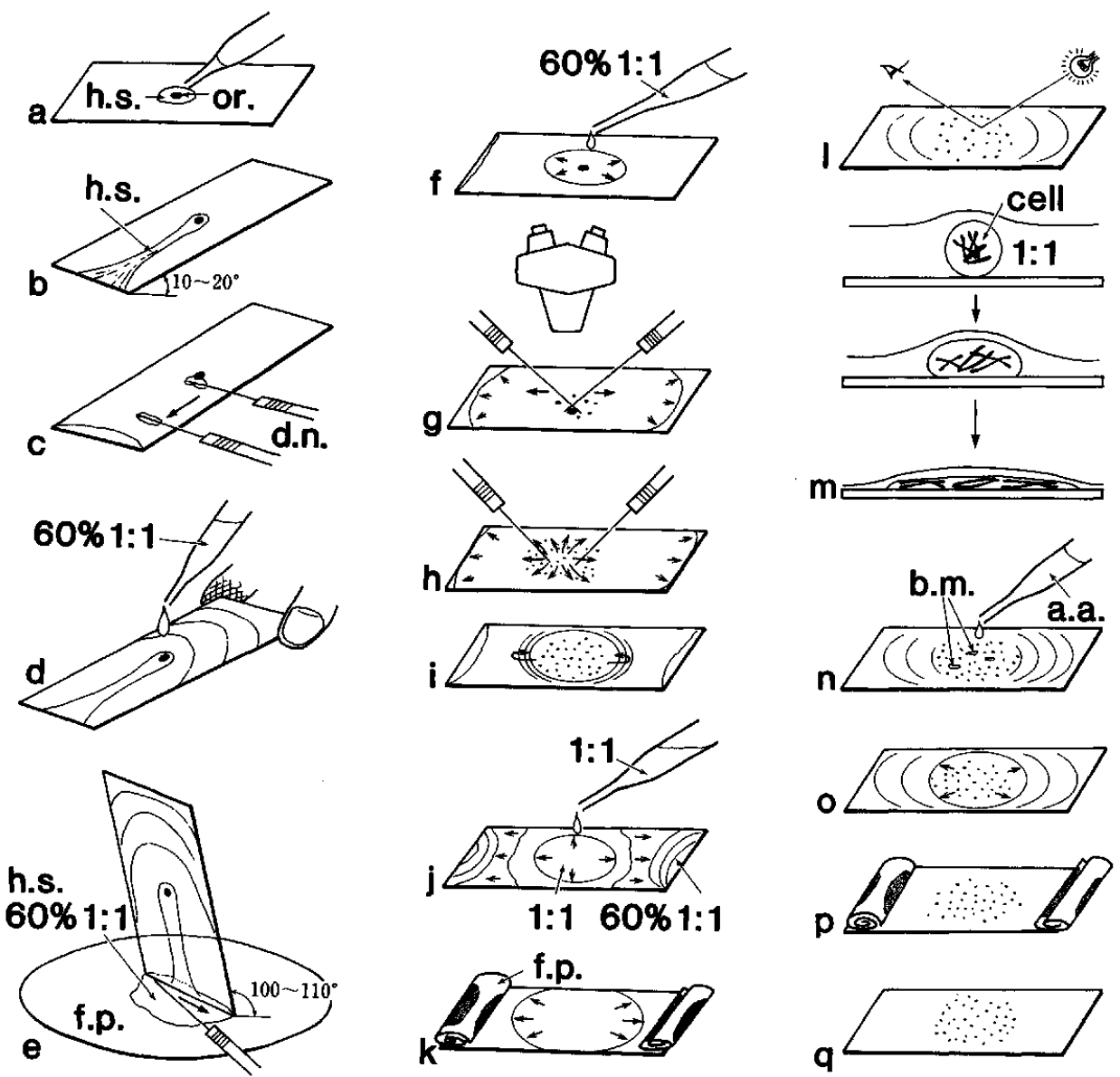

Fig. 3 A summary of the procedures used in chromosome preparations of organs from ants. (h.s. =hypotonic solution; or. =organ; d.n. =dissecting needles; f.p. =filter paper; b.m. =breakout of membrane of fixative; a.a. =acetic acid). For details see text. 
moves to margins of sldide, replaced by fixative II. (9) Remove fixative I using rolled filter paper (Fig. 3k); wait for 2-3 mins. Fixative II will cover the whole slide surface (unless the slide is oily) and will evaporate gradually (Fig. $3 \mathrm{~m}$ ). A few minutes later the cells can be seen under reflected light as small spots, spreading uniformly over the slide (Fig. 31). (10) As the film of fixative II is broken by evaporation (Fig. 3m), immediately add 2 drops of fixative III in the center of the spreading cells (Fig. 3n). This displaces fixative II outwards (Fig. 3o). (11) Remove fixative II using rolled filter paper (Fig. 3p) and allow the slide to dry completely (Fig. 3q). These procedures do not work well under extreme conditions $\left(>30^{\circ} \mathrm{C}\right.$ and $\left.90 \% \mathrm{rh}\right)$. The best preparations are obtained under conditions optimal for the evaporation of the fixatives $\left(20^{\circ} \mathrm{C}\right.$ temperature and $65 \%$ relative humidity).

After drying them for at least 1 day, stain preparations using freshly prepared Giemsa solution (3\% in M/15 Sørensen's pH 6.8 phosphate buffer: $\mathrm{Na}_{2} \mathrm{HPO}_{4} 4.75$ $\mathrm{g} / \mathrm{KH}_{2} \mathrm{PO}_{4} 4.5 \mathrm{~g} /$ d.w. $1000 \mathrm{ml}$ ) for 10 mins at room temperature. Each slide is then rinsed in a single pass through a $2 l$ beaker irrigated with running tap-water, and drained by being stood against a vertical surface.

For simplying descriptions, we cite haploid chromosome numbers in the text below for general karyological interpretations; diploid numbers are given also when necessary.

\section{OBSERVATIONS}

\section{1) The C-banding pattern in Myrmecia (pilosula) $n=1$}

A colony of M. (pilosula) collected by M.W.J.C. at Tidbinbilla Nature Reserve (near Canberra; see Table 1), and later maintained in culture at The University of New South Wales, Sydney, has yielded the lowest chromosome number known (or indeed possible) in any higher organism $(n=1,2 n=2)$ (Crosland and Crozier, 1986). This colony was sent to Japan in 1986 and has been subsequently cultured by H.T.I., for C-banding analysis. Seventy-five cells from the brains of 4 males showed the haploid number $n=1$ (Fig. 4a), while the diploid number $2 n=2$ (Fig. 4b) was recorded in 60 brain cells from 3 workers (Table 2). Chromosome polymorphism has not been detected, except for occasional polyploid cells $(2 n=2)$ in males. Under conventional nomenclature the chromosome is metacentric, with the ratio of the long arm to the short being $r=1.1$. The C-banding pattern in this species is somewhat complicated (Figs $4 \mathrm{c}$ and $4 \mathrm{~d}$ ). The chromosome has large pericentromeric heterochromatin blocks, with the block in the short arm about twice as large as that of the long arm. In addition, a small euchromatin section is present in the heterochromatin block of the short arm, dividing it into two pieces-a dot-like portion adjacent to the centromere, and a large distal mass (Fig. 4c). The conspicuous secondary constriction of the short arm is located at the junction between the inserted euchromatin and the distal heterochromatin 


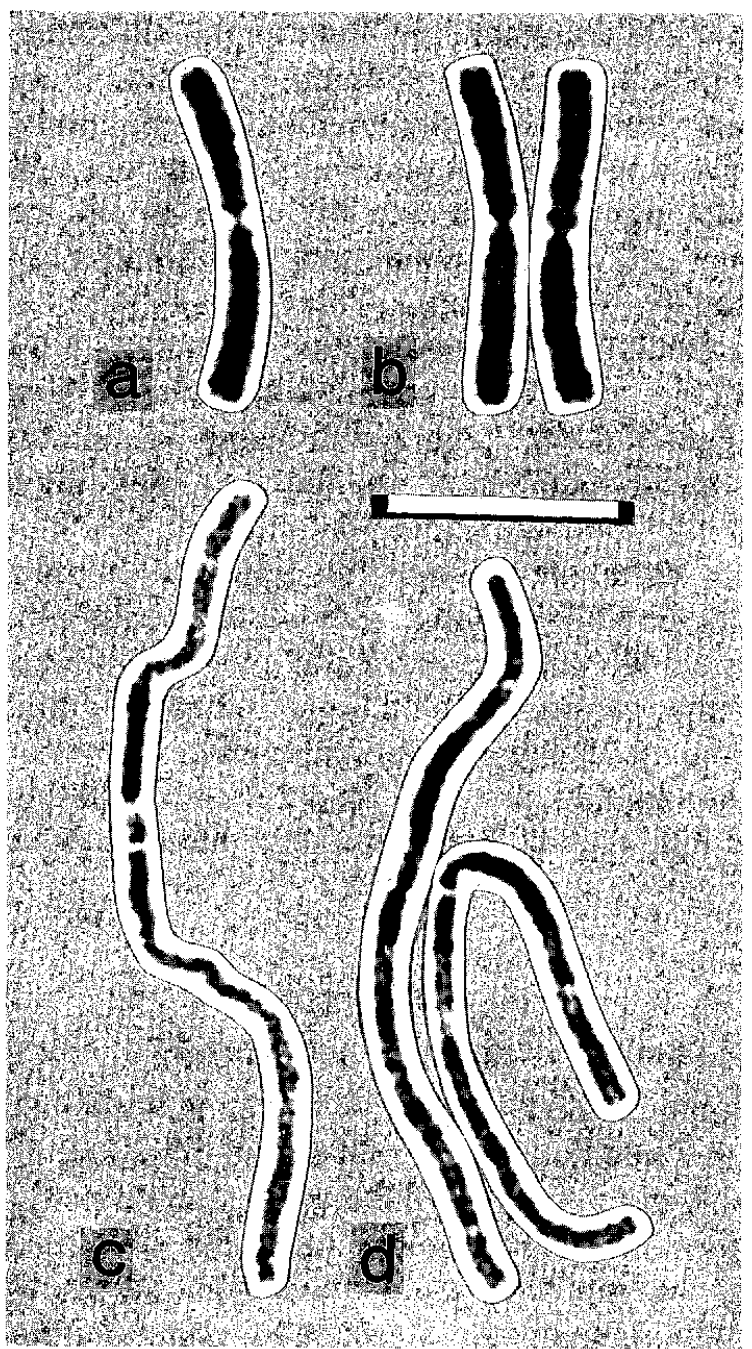

Fig. 4 Conventional (a, b) and C-banded (c, d) karyotypes of $M$. (pilosula) $n=1,2 n=2$. Scale bar represents $10 \mu \mathrm{m}$.

block (compare Figs 4a and 4c). The euchromatic section between the two heterochromatic blocks suggests that this chromosome could have arisen by translocation (or telomere fusion accompanying centromeric suppression) from an $\mathrm{n}=2$ karyotype such as found in Myrmecia (piliventris) (see below). Quite recently (after we submitted this paper to JJG), we actually found an $n=2$ karyotype in $M$. pilosula, of which detailed karyotype analyses will be published elsewhere. 
Table 2. Karyological data of Myrmecia and Ponera

\begin{tabular}{|c|c|c|c|c|}
\hline $\begin{array}{l}\text { Taxon } \\
\text { (Code of colony) }\end{array}$ & $\begin{array}{l}\text { No. of } \\
\text { chrom. } \\
\text { (n), } 2 \mathrm{n}\end{array}$ & $\begin{array}{l}\text { Ind. no. } \\
\text { obs. } \\
\text { (令), + }\end{array}$ & $\begin{array}{c}\text { Modal cell no. } \\
\text { obs. } \\
(\hat{\jmath}) \text {, }+\end{array}$ & Fig. \\
\hline \multicolumn{5}{|c|}{ Myrmecia (piliventris) complex } \\
\hline HI85-171 & $(32), 64$ & (3), 1 & (23), 10 & $5 e$ \\
\hline HI85-172 & 4 & 4 & 40 & $5 b, c$ \\
\hline HI85-188 & (2), 4 & (3), 2 & (77), 12 & $5 \mathrm{a}$ \\
\hline HI85-210 & 34 & 3 & 23 & $5 d$ \\
\hline HI85-211 & 4 & 2 & 36 & \\
\hline HI85-241 & 4 & 4 & 41 & \\
\hline HI85-302 & (3), (4), 6 & $1,1,1$ & $18,20,19$ & 6 \\
\hline \multicolumn{5}{|c|}{ Myrmecia (pilosula) complex } \\
\hline M. p. with $n=1$ & (1), 2 & (4), 3 & (75), 60 & 4 \\
\hline HI85-192 & 24,25 & 3,4 & 27,33 & \\
\hline HI85-193 & 25,26 & 4,3 & 34,28 & \\
\hline HI85-194 & 25,26 & 1,4 & 5,30 & \\
\hline HI85-195 & 23,25 & 1,3 & 22,27 & \\
\hline HI85-227 & 25,26 & 3,2 & 33,20 & $9 b, c$ \\
\hline HI85-228 & $24,25,26$ & $1,1,1$ & $12,10,8$ & $9 \mathrm{a}$ \\
\hline HI85-233 & 24,25 & 4,1 & 37,2 & \\
\hline HI85-374 & 31,32 & 3,1 & 18,12 & \\
\hline HI85-375 & 31,32 & 1,3 & 25,3 & \\
\hline HI85-376 & 23,24 & 2,3 & 22,20 & 11 \\
\hline HI85-378 & 31,32 & 2,2 & 22,21 & $8 a$ \\
\hline HI85-379 & 31,32 & 2,3 & 15,23 & $8 b, c$ \\
\hline \multicolumn{5}{|l|}{ Ponera scabra } \\
\hline \multirow[t]{2}{*}{ HI86-001 } & (3), (4) & (4), (5) & (67), (37) & 7 \\
\hline & 7,8 & 1,1 & 4,3 & \\
\hline HI86-002 & 7 & 1 & 10 & \\
\hline HI87-004 & 8 & 1 & 4 & \\
\hline HI87-005 & (3), (4), 8 & (2), (1), 1 & (37), (16), 6 & \\
\hline HI87-006 & $(4), 7,8$ & $(1), 3,2$ & $(20), 16,7$ & \\
\hline
\end{tabular}

今: male. 우: worker.

2) Karyotypic variation in the Myrmecia (piliventris) complex

Three colonies, each representing a different putative species of the $M$. (piliventris) complex, were collected in Canberra. Two (HI85-171 and -172) were taken behind the CSIRO Division of Entomology site, and one (HI85-210) on the nearby Australian National University campus (Table 1). Their workers are morphologically similar. If examined separately all three colonies may be identified as $M$. piliventris. On close comparison, however, clear morphological differences support the following chromosomal evidence that they are separate species. Their karyotypes differ markedly. Series -171 has high chromosome 
number $n=32$ (incorrectly cited as $n=34$ in Imai and Taylor, 1985), -210 has $n=17$, and -172 has $n=2$ (Fig. 5). For detailed karyological data see Table 2. The $2 \mathrm{n}=4$ karyotype comprises 2 pairs of subtelocentrics $(2 \mathrm{~K}=4 \mathrm{ST})$. The chromosomes are of about the same size, and both have well-developed proximal C-bands on their long arms (Fig. 5c). Chromosome 1 is monomorphic, but chromosome 2 is polymorphic for C-banding pattern and short-arm size (Fig. 5c). Another colony (HI85-188), the workers of which closely match the apparently conspecific Canberra $M$. (piliventris) $2 n=4$ specimens in karyotype and general morphology, was collected on Jerrabomberra Hill (near Queanbeyan, N.S.W.), and two more such colonies (HI85-211, -241) were taken near Nelligen Creek Bridge (west of Nelligen, NSW) (Tables 1 and 2). This species, identified as $M$. piliventris by Imai and Taylor (1986), thus appears to be fairly widely distributed, at least in southeastern New South Wales.

The karyotypes of $M$. (piliventris) $2 n=34$ (i.e., $\mathrm{n}=17$ ) and $M$. (piliventris) $n=32(2 n=64)$ are quite different from that discussed above. The former com-

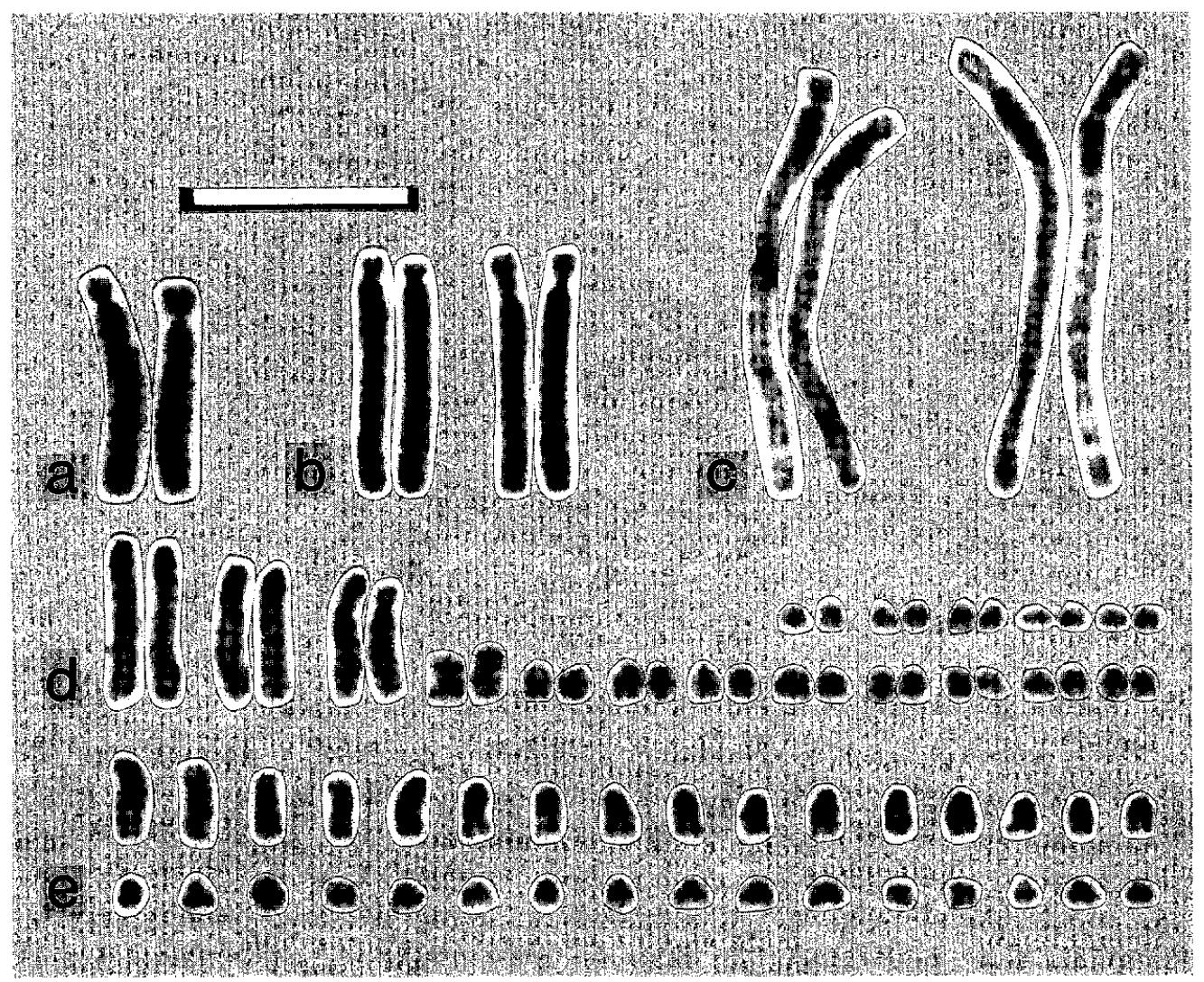

Fig. 5 Karyotypes of members of the $M$. (piliventris) complex. a. HI85-172 $(\mathrm{n}=2) . \quad \mathrm{b}$ and $\mathrm{e}$. HI85-172 $(2 n=4)$. d. HI85-210 $(2 n=34)$. e. HI85-171 $(n=32)$. Scale bar represents $10 \mu \mathrm{m}$. 
prises 3 pairs of extremely large acrocentrics, 1 pair of small metacentrics, and 13 pairs of minute acrocentrics (Fig. 5d). The number of minute acrocentrics is even more remarkable in $M$. (piliventris) $n=32$ (Fig. 5e). Here all chromosomes except 3 large-sized STs are minute acrocentrics with well-developed heterochromatic short-arms. The large STs have large pericentromeric heterochromatin blocks, which could be derived secondarily by centric fusion, as is the case in $M$. (pilosula) (Fig. 9). No significant homologies are found among the karyotypes $n=2,-17$, or -32 . Similar phenomena were observed previously in 2 putative species of the $M$. (fulvipes) complex (Imai et al., 1977). Colonies AAGR-14 and AAGT-12, from Leumeah $\left(34^{\circ} 03^{\prime} \mathrm{S}, 150^{\circ} 50^{\prime} \mathrm{E}\right)$, near Cambelltown, N.S.W., had $n=6$ and $2 n=12$, while AAHM-1, from Piccadilly Circus $\left(35^{\circ} 22^{\prime} S\right.$, $\left.148^{\circ} 49^{\prime} \mathrm{E}\right)$, near Canberra, had $\mathrm{n}=30(2 \mathrm{n}=60)$.

3) Some unusual translocations accompanying de novo formation or suppression of the centromere

A colony of a further putative species of the $M$. (piliventris) complex was collected near Ravenshoe in north eastern Queensland (HI85-302) (Table 1). In general features its workers are close to the three Canberra putative (piliventris) species, but morphological differences justify their separated specific status. Chromosome preparations from two males and a worker have been analysed (Table 2). The cells of the first male have three chromosomes comprising two large subtelocentries (STs) and a minute metacentric (M) $(K=1 M+2 S T$; Fig. 6a), while worker brain cells have 3 pairs of chromosomes (Fig. $6 \mathrm{~b}$ ), yielding a chromosome number of $n=3$ and $2 n=6$. C-banding analysis reveals that the STs are almost identical to those of $M$. (piliventris) $2 n=2$ in size, and in the distribution of heterochromatin (compare Figs 5 and 6). The origin of the minute $M$ (chromosome 3) is not clear.

An unusual chromosomal mutation has been observed in this species. The second male yielded a chromosome number of $n=4$, and its karyotype is quite different from that described above. It comprises an extremely large metacentric, 2 small subtelocentrics, and a minute metacentric (i.e., $\mathrm{K}=2 \mathrm{M}+2 \mathrm{ST}$ ) (Fig. 6c). The long arms of the small STs are entirely heterochromatic (C-band positive). It is noteworthy that the euchromatic arms of the large $M$ and the heterochromatic long arms of the two small STs in the $n=4$ karyotype together correspond roughly in size to the euchromatin regions and heterochromatin blocks of the large STs of the $n=3$ karyotype (compare Figs $6 a$ and $6 c$ ). This suggests strongly that the mutant $n=4$ male karyotype resulted from an incomplete reciprocal translocation, which occurred at the heterochromatin/euchromatin junction in the long arms of the two large STs of the $n=3$ karyotype (Fig. 6d). The mutant chromosome is therefore termed $\mathrm{T}(1,2)$. If this scenario is accepted we must also accept the de novo appearance of the centromere in the mutant large $\mathrm{M}$; since this chromosome was observed to be stable in all cells examined, and no 


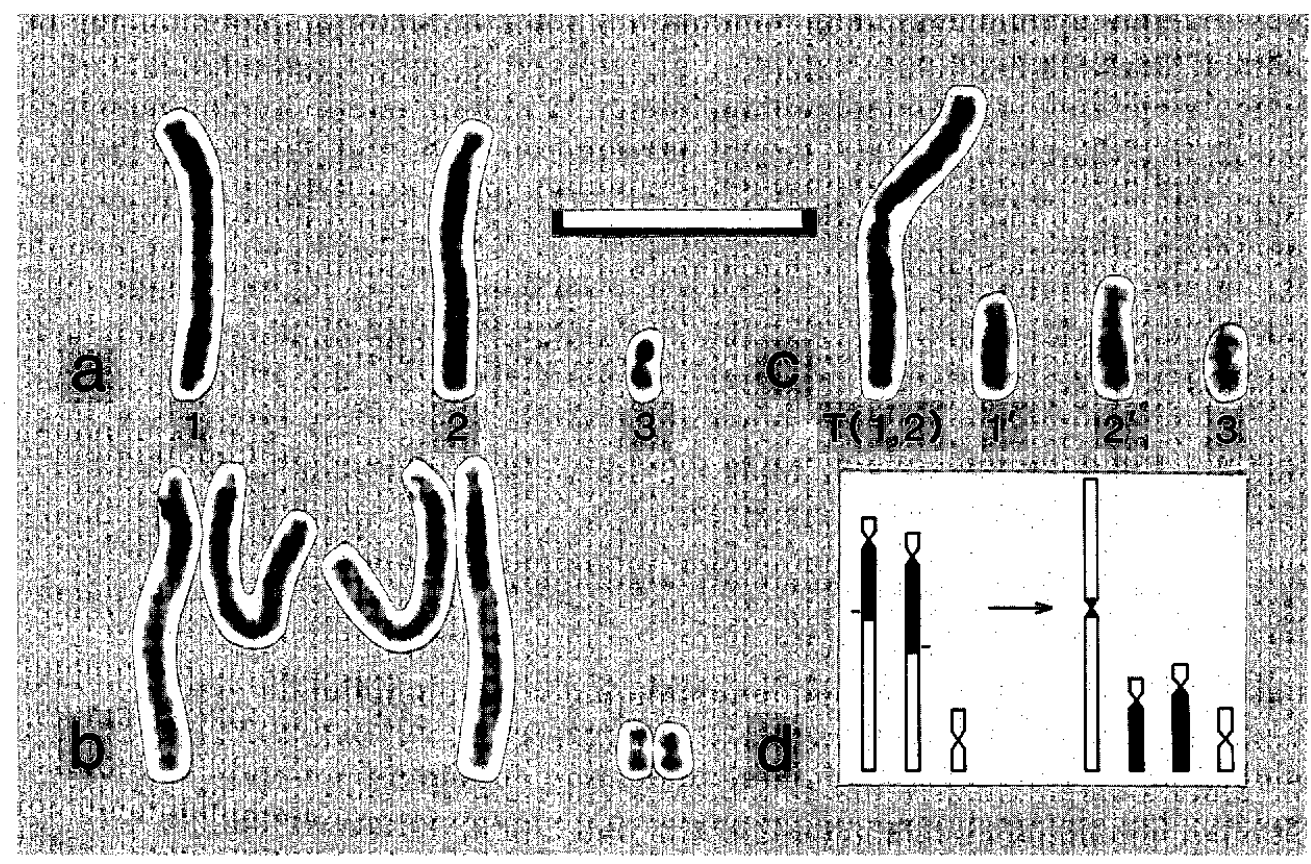

Fig. 6 Karyotypes of Myrmecia (piliventris) $2 n=6$ (HI85-302). a. $n=3$. b. $2 n=6$. c. $n=4$ with translocation $T(1,2)$. d. A schematicrepresentation of the translocation involved. Small bars indicate the breakage points hypothecated. Black sections represent constitutive heterochromatin. $\mathrm{I}^{\prime}$ and $2^{\prime}$ indicate derivatives from chromosomes 1 and 2 in the normal karyotype. Scale bar represents $10 \mu \mathrm{m}$.

abnormal mitotic divisions were detected (e.g., acentric fragments or nondisjunction resulting from absence of a centromere). In addition, the naked chromosome terminals of the two small STs induced by translocation would appear to have been stable through many cell divisions. We have no experimental data on the molecular mechanism, but the cytological evidence indicates two alternative possibilities: (1) both the telomere and the centromere appeared de novo, or (2) dormant telomeres incorporated in the heterochromatin block were activated by the rearrangement. We believe the latter possibility to be more likely (see below).

A further extraordinary translocation has been found in Ponera scabra. Its presence was first suggested by Imai and Kubota (1972), based on their observations of $2 n=7$ karyotypes in workers, and $n=4$ in males. In this study two classes of males have been found, respectively with $n=3$ and $n=4$ karyotypes (Fig. 7), while 10 additional workers examined had either $2 n=7$ or $2 n=8$, confirming the previous observations (Table 2). Detailed analysis of C-banding reveals that the $n=3$ male karyotype is derived from $n=4$ by a kind of 'dicentric translocation' between the short arm of chromosome 3 and the long arm of 


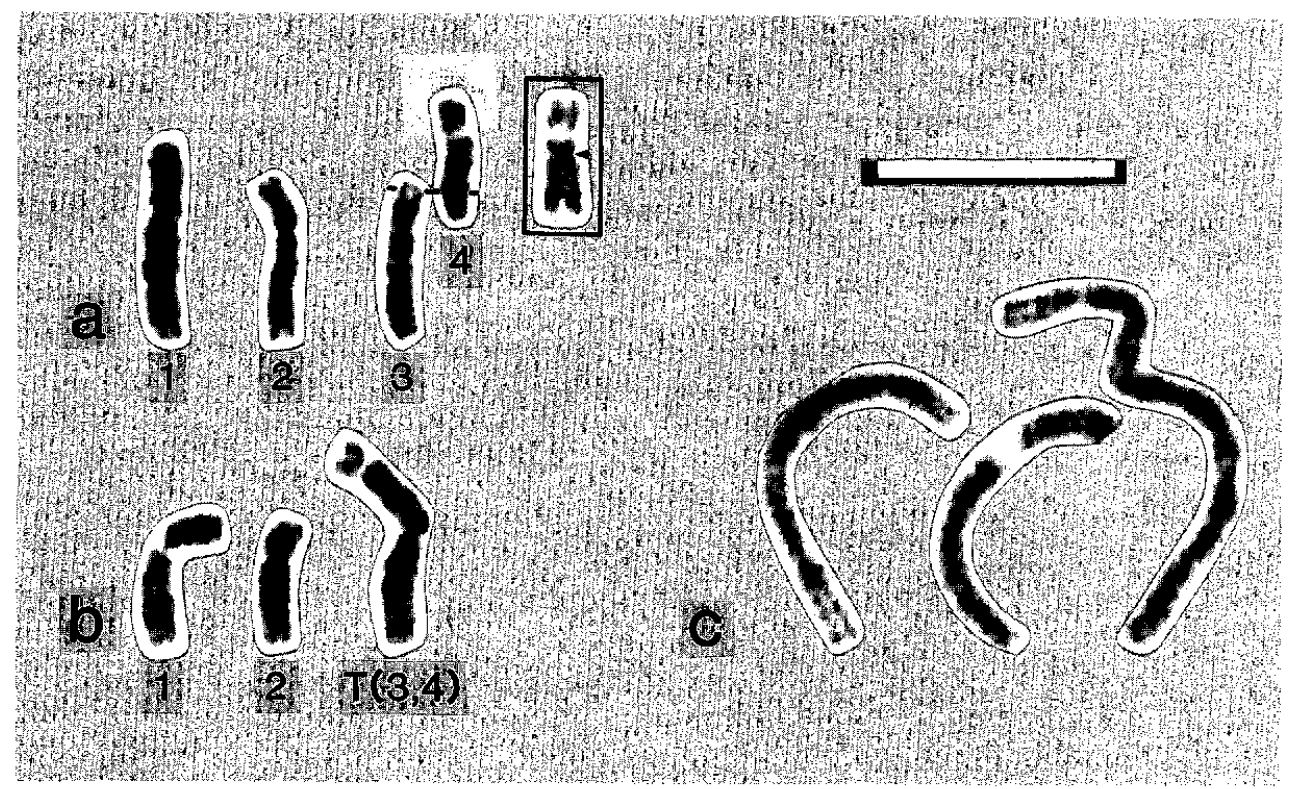

Fig. 7 Karyotypes of Ponera scabra. a. A normal haploid karyotype $(\mathrm{K}=4 \mathrm{SM})$. Chromosome 4 inserted to show the primary constriction (arrow head). B. A mutant karyotype with the T(3, 4) translocation. c. A C-banded karyotype with translocation. Scale bar represents $10 \mu \mathrm{m}$.

chromosome 4 (Figs 7a and 7b). The mutant chromosome, which is symbolised here as $\mathrm{T}(3,4)$, has derived its centromere from chromosome 3 . This is detectable because of a primary constiction (Fig. 7b). The centromere of chromosome 4 is, however, not clearly discernible (Figs $7 \mathrm{~b}$ and $7 \mathrm{c}$ ). $\quad \mathrm{T}(3,4)$ always behaves as if it is a monocentric chromosome. It has been transmitted stably in the Manazuru population for at least 15 years, indicating that queens heterozygous for $\mathrm{T}(3,4)$ are viable and fertile. This phenomenon is not limited to the Manazuru area. It has also been observed in samples of $P$. scabra taken near Odawara $\left(35^{\circ} 15^{\prime} \mathrm{N}\right.$, $\left.139^{\circ} 10^{\prime} \mathrm{E}\right), 30 \mathrm{Km}$ to the northeast. If our interpretation is correct, $\mathrm{T}(3,4)$ carriers should have partial deletions at the tips of the long and short arms of the relevant chromosomes (see Fig. 7a). They are, nonetheless, viable, and no morphological differences have been detected between $n=3$ and $n=4$ males. It remains to be seen whether $2 n=6$ workers homozygous for the translocation are viable, considering the partial deletion.

\section{4) Chaotic chromosomal polymorphisms in the Myrmecia (pilosula) complex}

Variations in chromosome number $(2 \mathrm{n}=9,10,30,31)$ in $M$. (pilosula) were first observed by Imai et al. (1977), who suggested that they arose at least in part from translocations, pericentric inversions, or size variation in the heterochromatic short arms. More recently, Crosland et al. (1988) suggested that more complex rearrangements must have occurred to yield the wide range of chromosome 
numbers in this population $(2 n=2,9,10,18-32)$. Detailed karyotypic analyses of $M$. (pilosula) will be published elsewhere. Here we report only chromosomal polymorphism of three local populations, from Piccadilly Circus, and Condor Creek ACT, and from Mongarlowe, NSW (Table 1). These provide useful information in developing a model of spontaneous chromosomal mutation in ants (Table 3).

Table 3. Intra-and inter-colonial variations of chromosome numbers in Myrmecia pilosula

\begin{tabular}{|c|c|c|c|c|c|c|c|c|c|c|c|c|c|c|}
\hline \multirow{2}{*}{$\begin{array}{l}\text { Locality } \\
\text { Code no. } \\
\text { HI85- } \\
\text { Chrom. no. 2n }\end{array}$} & \multicolumn{8}{|c|}{ Mongarlowe } & \multirow{2}{*}{$\frac{\text { Condor creek }}{376}$} & \multicolumn{5}{|c|}{ Piccadilly circus } \\
\hline & 192 & 193 & 194 & 195 & 227 & 228 & 233 & Total & & 374 & 375 & 378 & 379 & Tota \\
\hline 23 & & & & 1 & & & & 1 & 2 & & & & & \\
\hline 24 & 3 & & & & & 1 & 4 & 8 & 3 & & & & & \\
\hline 25 & 4 & 5 & 1 & 3 & 3 & 1 & 1 & 18 & & & & & & \\
\hline 26 & & 3 & 4 & & 2 & 1 & & 9 & & & & & & \\
\hline 31 & & & & & & & & & & 3 & 1 & 2 & 2 & 8 \\
\hline 32 & & & & & & & & & & 1 & 3 & 2 & 3 & 9 \\
\hline Total & 7 & 8 & 5 & 4 & 5 & 3 & 5 & 36 & 5 & 4 & 4 & 4 & 5 & 17 \\
\hline
\end{tabular}

Piccadilly Circus. Seventeen workers from four colonies were examined; nine had $2 n=32$ (Fig. 8a), and eight $2 n=31$ (Figs $8 b$ and $8 c$ ). The $2 n=32$ karyotype is standard in this population. Basically it comprises 32 acrocentrics, but its chromosomes show remarkable variation in the size of their heterochromatic 'short' arms, which are often longer than the euchromatic arms. Moreover, some homologous pairs differ in the size of their short arms (e.g., chromosomes 2, 3, 5, and 7 in Fig. 8a; and 2, 3, 6, and 16 in Fig. 8b). These data suggest the frequent occurrence of tandem growth of constitutive heterochromatin (t.g.c.h.), with secondary elimination of constitutive heterochromatin (e.c.h.). We denote these acrocentrics with relatively long heterochromatic short arms as 'pseudoacrocentrics', and symbolise them $A^{\mathrm{M}}$. The odd-numbered $2 n=31$ karyotypes are derived secondarily from $2 \mathrm{n}=32$ by the deletion of one chromosome, yielding a monosomic. Each mutant worker has a different monosomic-e.g., compare chromosome 14 (Fig. 8b) and chromosome 1 (Fig. 8c). Since each monosomic chromosome is stable in each ant examined, and since there are no data suggesting mosaicism of chromosome number (i.e., $2 n=31 / 32$ ), chromosomal deletion must occur during the meiotic process, and not after fertilization. Despite the frequent deletion of chromosomes, which was observed in ca. $50 \%$ of individuals examined, the workers from these colonies are essentially uniform in morphology.

Mongarlowe. Four consecutive chromosome number $(2 n=23,24,25,26)$ were found in this population (Table 1). Most colonies investigated included animals 


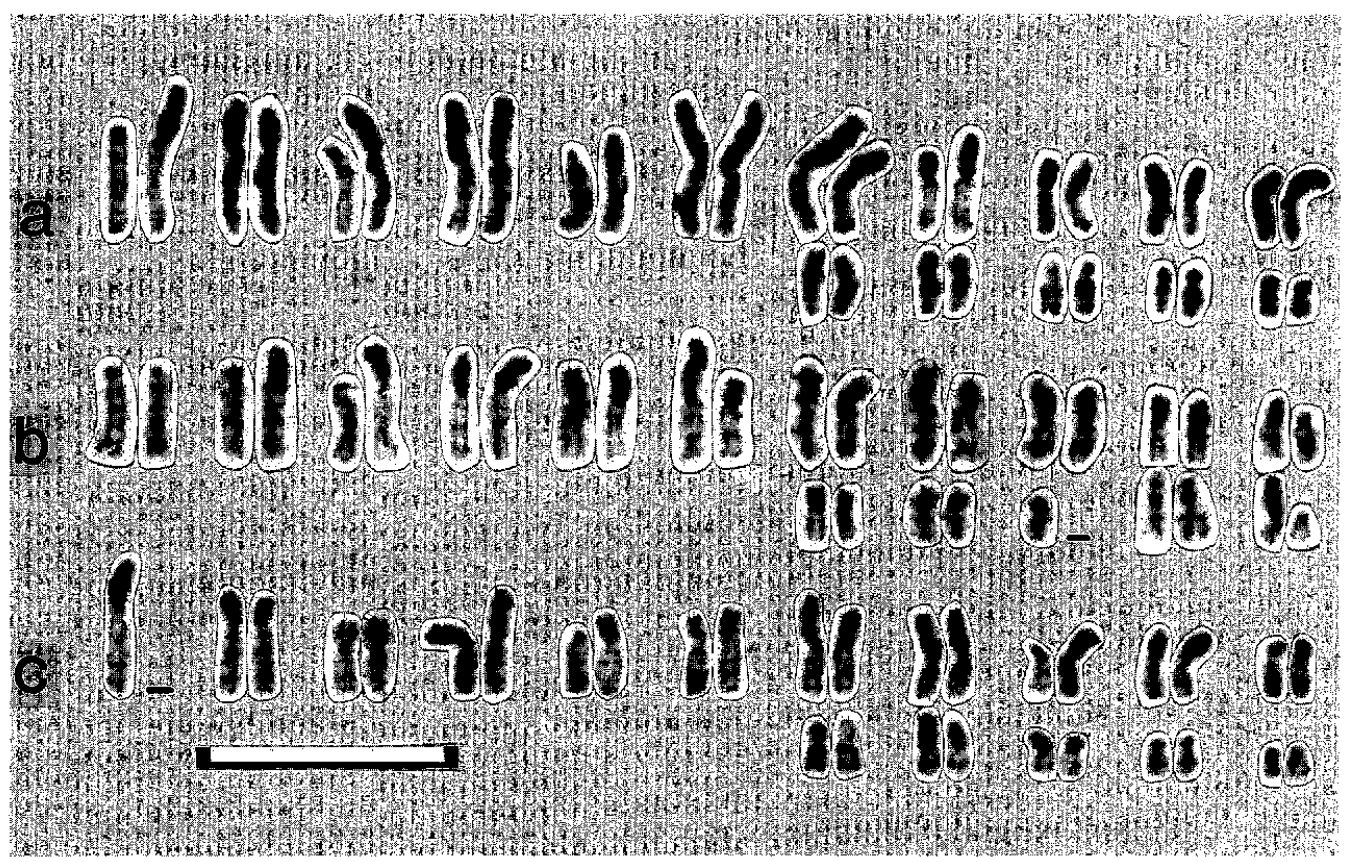

Fig. 8 C-banded karyotypes of $M$. (pilosula) from the Piccadilly Circus. a. $2 n=24 . \quad$ b. and c. $2 \mathrm{n}=26$. Small bars indicate deletions (monosomy). Seale bar represents $10 \mu \mathrm{m}$.

with either of two pairs of consecutive numbers, $2 n=24 / 25$, or $25 / 26$; one colony had 23/25, and one $24 / 25 / 26 ; 2 n=25$ was most frequent overall. These karyotypes were extraordinarily disordered by a series of chromosomal rearrangements, which included monosomy, trisomy, centric fusion, centric fission, pericentric inversion, and fluctuation of heterochromatic short arms (Fig. 9). Detailed Cbanding analyses revealed that these karyotypes always included 5 pairs of $M$ or SM, and 6 pairs of $A^{\mathrm{M}}$ chromosomes. The former exhibited complicated polymorphisms, including centric fusion (chromosomes 1 and 2; Fig. 10a), centric fission (chromosomes 3 and 5-Fig. 10c), and centric fission accompanying pericentric inversion (chromosome 4; Fig. 10b). In the pseudo-acrocentrics variations in the size of heterochromatic short arms and monosomy were frequent, the latter much as in the Piccadilly Circus population (Fig. 10d). Chromosomes 1 and 2 have large-sized pericentromeric heterochromatin blocks, and for this reason we assume that they originated from pseudo-acrocentrics by centric fusion (or more precisely by dicentric fusion, or telomere fusion, as will be discussed elsewhere (Fig. 10a)). In contrast, chromosomes 3 and 5 are normal meta- or submetacentrics, in which pericentromeric heterochromatin is not abundant (Fig. 9a). The 4 telocentric derivatives of chromosome 3, illustrated in Fig. 9c, correspond respectively to the long and short arms of the submetacentric chromosome 3 in Fig. 9a. These data suggest that chromosomal alterations have occurred by 


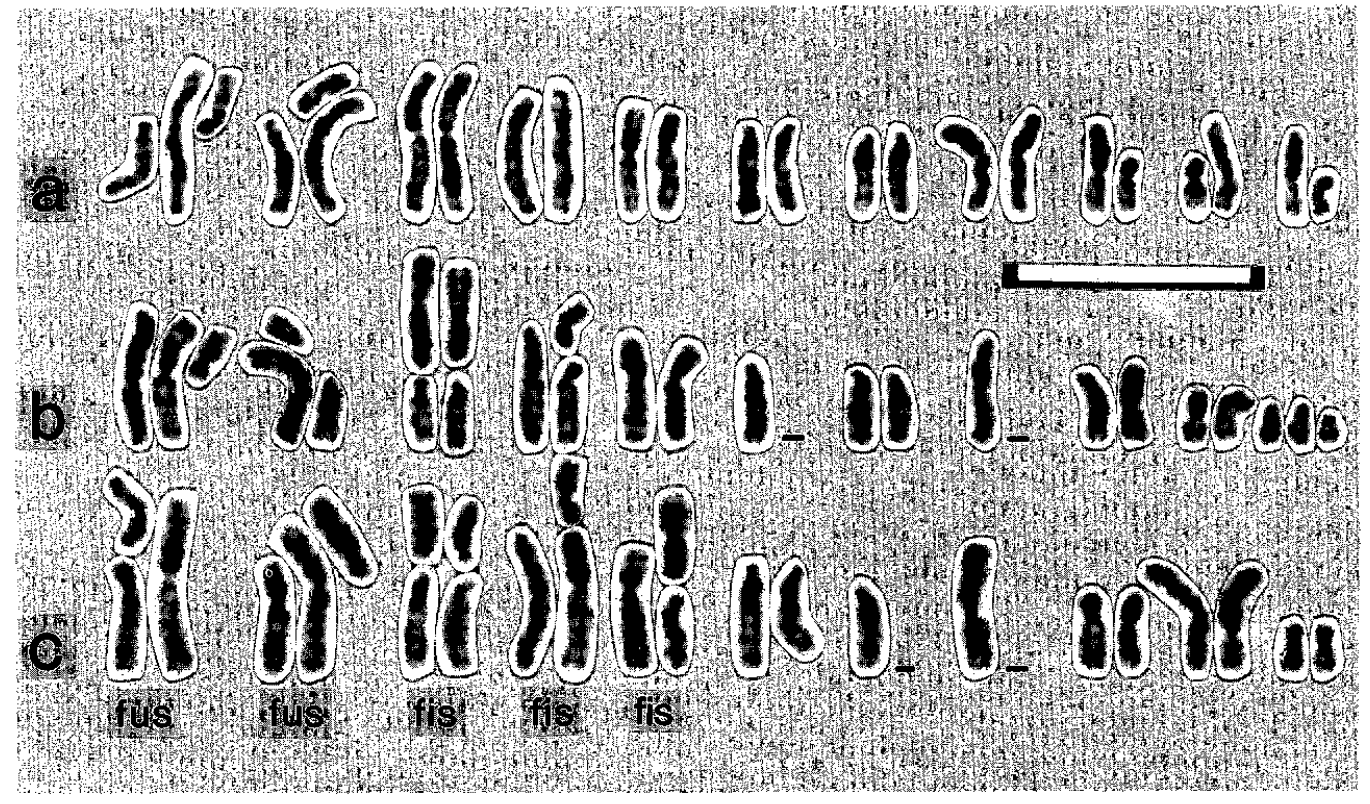

Fig. 9 C-banded karyotypes of $M$. (pilosula) from the Mongarlowe population. (fus=centric fusion; fis $=$ centric fission). Scale bar represents $10 \mu \mathrm{m}$.
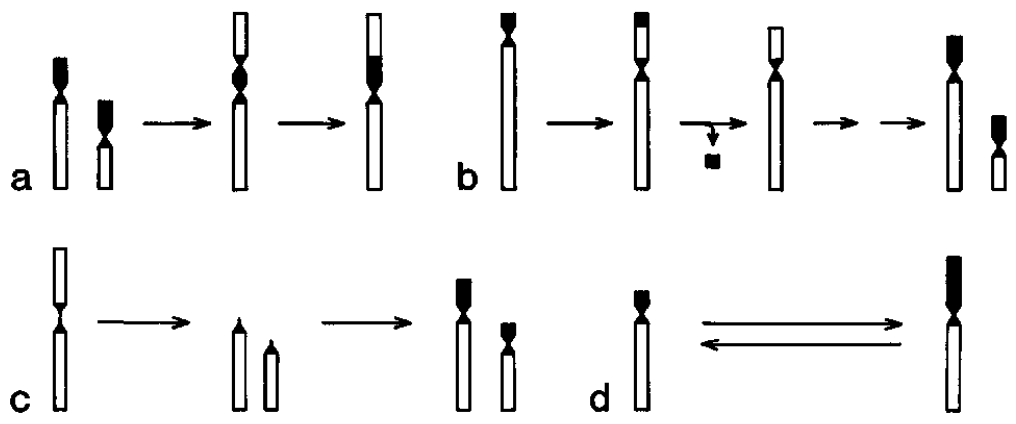

Fig. 10 Schemes of structural chromosomal mutations involved in the karyotypic alterations of $M$. (pilosula). See figures 8 and 9.

centric fission (Fig. 10c), and successive increase of heterochromatic short arms by t.g.c.h. The heteromorphism of chromosome 4 (A/SM), illustrated in Fig. 9a, obviously results from pericentric inversion, while the SM homologoue is divided into the two pseudo-acrocentrics shown in Figs $9 \mathrm{~b}$ and $9 \mathrm{c}$. Although a karyotype including homomorphic acrocentrics (A/A) has not yet been found, the morphological alterations of chromosome 4 may reasonably be considered as a result of the combination of pericentric inversion, centric fission, and tandem growth of constitutive heterochromatin (t.g.c.h.) (Fig. 10b).

Condor Creek. Five workers from a single colony were karyotyped. Two had 


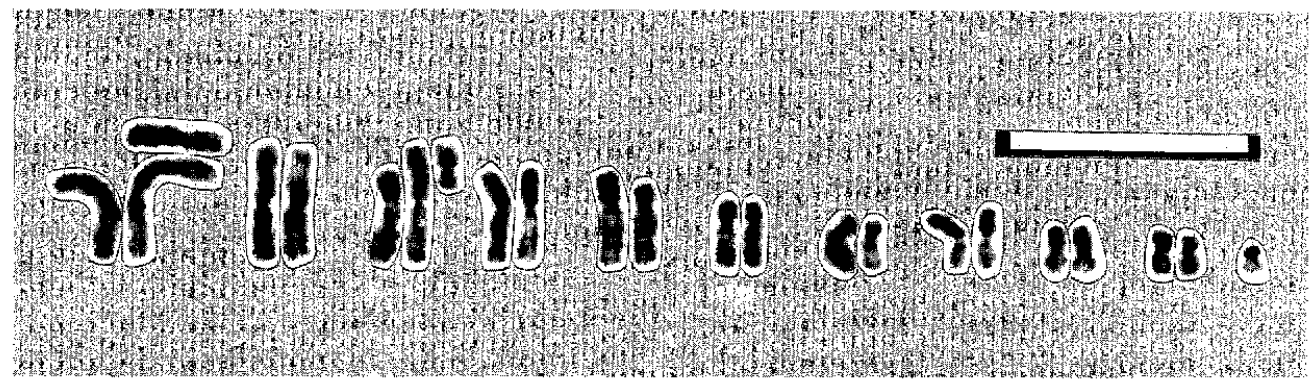

Fig. 11 A C-banded karyotype of $M$. (pilosula) from the Condor creek population. Scale bar represents $10 \mu \mathrm{m}$.

$2 \mathrm{n}=23$, and three $2 \mathrm{n}=24$ (Table 1, Fig. 11). Condor Creek is about $5 \mathrm{Km}$ from Piccadilly Circus, on the same mountain range, but at a much lower elevation (680 $\mathrm{m}$ versus $1240 \mathrm{~m}$ ). This $M$. (pilosula) series is karyotypically similar to those from Mongarlowe (which were taken about $90 \mathrm{Km}$ eastwards, at an elevation of around $650 \mathrm{~m})$. The standard karyotype $(2 \mathrm{n}=24)$ comprises 3 pairs of large metacentrics (chromosomes 1, 2 and 3) induced by dicentric fusion or telomere fusion, by comparison with the Picadilly Circus population, and 8 pairs of pseudoacrocentrics. The largest metacentric has been observed only in Condor Creek preparations, but the other two metacentrics correspond to chromosomes 1 and 2 of the Mongarlowe population (compare Figs 9 and 11). In the $2 n=23$ karyotype one of the $\mathrm{A}^{\mathrm{M}}$ chromosomes is monosomic (chromosome 11 in Fig. 11).

\section{DISCUSSION}

\section{1) Modes of spontaneous chromosomal mutation in ants}

More than 500 ant species have now been karyotyped (Crozier, 1975; Imai et al., 1977; Imai et al., 1984; Hauschteck-Jungen and Jungen, 1983). Eight categories of spontaneous chromosomal mutations are evident: (1) Robertsonian rearrangement, (2) translocation, (3) pericentric inversion, (4) size variation of heterochromatic short arms by t.g.c.h. and e.c.h., (5) partial deletion or duplication, (6) supernumerary (B-) chromosomes, (7) trisomy or monosomy, and (8) polyploidy. In order to distinguish high- from low-numbered ant karyotypes, they have been divided into those with $n>12$ and those with $n \leq 12$ for the quantitative discussions below, because (1) the frequency distribution of ant chromosome numbers is bimodal, with the antimode at $n=12$ to 13 (Fig. 1), (2) the majority of known hymenopteran karyotypes other than those of ants have $n \leq 12$ (Imai, 1986), and (3) recognition of this dichotomy seems to be essential for the analysis of karyotype evolution in ants.

Robertsonian rearrangement: Forty nine cases of Robertsonian polymorphism have been recorded from 25 species, all of which have relatively high chromosome 
number ( $n=12$ to 41 ) (Table 4). But these rearrangements are also found in species with $n \leq 12$. Some fusions or fissions are known in karyotypes with $n=9$ and 10 (in Tetramorium (=Xiphomyrmex); Imai et al., 1977), and $\mathrm{n}=11$ (in Pachycondyla astuta HI85-54; Imai et al., 1985). Nevertheless, Robertsonian rearrangements tend to occur preferentially in species with $n>12$ (Fig. 1).

Translocation: Despite the well-established view that translocations have not contributed much to the evolution of animal karyotypes (White, 1973: 285), 19 separate translocations have been reported from 13 ant species (Table 5). This suggests that translocations might be less deleterious in ants than in other animals. In Ponera scabra, for example, cytologically stable translocation heterozygosity (Fig. 7) has been observed for more than 15 years in the Manazuru population, and some translocations seem to have been fixed during karyotype

Table 4. Robertsonian rearrangements detected in ants

\begin{tabular}{|c|c|c|}
\hline Taxon (code no.) & $\begin{array}{l}\text { Chrom. no. } \\
\text { (n) } 2 n\end{array}$ & Authors \& remarks \\
\hline 1. Pachycondyla astuta (HI85-54) & 22 & $\mathbf{a}$ \\
\hline 2. Myrmecia (pilosula) (HI85-228) & $24,25,26$ & Present paper \\
\hline 3. Myrmecia (pilosula) (HI85-376) & 23,24 & Present paper \\
\hline 4. Camponotus sp. 10 (HI83-41, 42) & $(13,14)$ & b \\
\hline 5. Acropyga acutiventris (HI83-28, 119) & 28,29 & b \\
\hline 6. Pheidole sp. 5 (HI82-38) & $(16,17)$ & c \\
\hline 7. Vollenhovia sp. 2 (HI83-93, 95) & 33,34 & b \\
\hline 8. Prenolepis sp. (HI82-60, 74) & 34,36 & c \\
\hline 9. Camponotus sp. 9 (HI78-26) & 34,35 & $d$ \\
\hline 10. Tetramorium sp. 3 (HI78-163, 172) & 35,36 & d \\
\hline 11. Rhytidoponera metallica (Eastern form) & $36-46$ & $\mathbf{e}, \mathbf{k}$ \\
\hline 12. Pheidole nodus & $(17-20) 37-39$ & $f, g$ \\
\hline 13. Camponotus sp. 8 (HI83-23) & 38,39 & $\mathrm{~b}$ \\
\hline 14. Camponotus sp. 1 (HI84-45, 52) & 38,39 & a \\
\hline $\begin{array}{l}\text { 15. Pachycondyla rubra }=\text { Mesoponera sp. } 2 \\
(\mathrm{HI} 83-3,11,12)\end{array}$ & 38,40 & $\mathbf{b}$ \\
\hline 16. Camponotus crassisquamis (HI78-44, 10) & 39,40 & $d$ \\
\hline 17. Rhytidoponera maniae & $39-48$ & e \\
\hline 18. Messor sp. (HI78-49) & 41 & d \\
\hline 19. Sphinctomyrmex steinheili & 45,46 & e \\
\hline 20. Aphaenogaster longipus & 45,46 & e \\
\hline 21. Myrmecia forficata & 50,51 & $\mathrm{e}$ \\
\hline 22. Vollenhovia sp. 1 (HI83-46, 69) & 49,50 & $\mathbf{b}$ \\
\hline 23. Myrmecia pyriformis & (41) 81 & $\mathbf{e}$ \\
\hline
\end{tabular}

N. B. a. Imai et al. (1985), b. Imai et al. (1984b), c. Goñi et al. (1982), d. Imai et al. (1984a), e. Imai et al. (1977), f. Imai and Kubota (1972), g. Imai and Kubota (1975), h. Crosland and Crozier (1986), i. Imai (1974), j. Imai and Yosida (1966), k. Crozier et al. (1969), l. Crozier (1986), and m. Crozier (1970). These abbreviations are also used in Tables 5, 6, and 7. 
Table 5. Translocations detected in ants

\begin{tabular}{|c|c|c|}
\hline Taxon (code no.) & Chrm no. & Authors \& remarks \\
\hline 1. Myrmecia pilosula & (1) 2 & $\begin{array}{l}\mathrm{h} \\
\text { Present paper }\end{array}$ \\
\hline 2. Myrmecia pilosula & 9,10 & e \\
\hline 3. Myrmecia (piliventris) & $(3,4) 6$ & Present paper \\
\hline 4. Ponera scabra & $(3,4) 7$ & $\begin{array}{l}\text { f } \\
\text { Present paper }\end{array}$ \\
\hline 5. Triglyphothrix lanuginosa & 14 & d \\
\hline " walsi & 14 & d \\
\hline 6. Iridomyrmex $s p .15$ & 18 & e \\
\hline 7. Pheidole sp. 29 & 20 & e \\
\hline 8. Pheidole sp. 30 & 20 & e \\
\hline 9. Pheidole sp. 17 (HI83-27) & 20,21 & b \\
\hline 10. Camponotus dolensis & 20 & d \\
\hline " mitis & 20 & d \\
\hline 11. Monomorium indicum & 20,21 & b \\
\hline 12. Brachyponera sp. (HI82-72) & 22 & c \\
\hline 13. Rhytidoponera metallica (Western form) & $22,23,24$ & e \\
\hline
\end{tabular}

evolution in Tetramorium (=Triglyphothrix) and Camponotus (Imai et al., 1984). The male haploidy sex-determining system could be influential in this apparent toleration of the unbalanced derivatives of translocation.

In contrast to Robertsonian rearrangements, translocations appear preferentially in ant species with low-numbered karyotypes $(n \leq 12)$ (Fig. 1). If the frequency of translocation polymorphisms is determined by the balance between mutation and selection, then they should be found more frequently in ant species with higher chromosome numbers $(n>12)$ than in those with lower numbers of chromosomes ( $\mathrm{n} \leq 12$ ) (Imai et al., 1986). Briefly, if the probability of occurrence of inversion (In) and translocation (Tr) per haploid karyotype is proportional to the probability of two random breakpoints occurring either on one chromosome (inversion), or on non-homologous chromosomes (translocation), In and $\mathrm{Tr}$ are given by

$$
\begin{aligned}
& \text { In }=\sum_{i=1}^{n} C_{i}^{2} \\
& \operatorname{Tr}=\sum_{i=1}^{n} \sum_{j=1}^{n} C_{i} C_{j}=1-\sum_{i=1}^{n} C_{i}^{2}
\end{aligned}
$$

where $\operatorname{In}+\operatorname{Tr}=1$, and $C_{i}$ and $C_{j}$ are two non-homologous chromosomes $(i \neq j)$. It follows that, in an hypothetical karyotype having $n$ equal-sized chromosomes, $C_{i}=1 / n$ and then $\operatorname{In}=n(1 / n)^{2}=1 / n$; i.e., the probability of occurrence of translocations increases as chromosome number increases $(\operatorname{Tr}=1-1 / n)$. Although this calculation is over-simplified, it is clear that the distribution of spontaneous 
translocations in ants shows the contrary.

Inversion: There are technical difficulties in detecting paracentric inversions, but 17 pericentric inversions have been observed in 15 species (Table 6). They are distributed almost uniformly among low and middle-numbered karyotypes $(n=5-24)$, and have not been reported in species with $n>25$. This distribution pattern differs from those of other kinds of rearrangements discussed above, and this could be due to the stochastic characteristic of inversion already mentioned. It could also reflect the historical probability like that most higher-numbered karyotypes $(n=25-41)$ in which acrocentrics predominate result from relatively recent centric fissions. These acrocentrics might not have had sufficient time to change into metacentrics by pericentric inversion.

Table 6. Pericentric inversions detected in ants

\begin{tabular}{rll}
\hline \hline Taxon (code no.) & $\begin{array}{c}\text { Chrom. no. } \\
(\mathrm{n}) 2 \mathrm{n}\end{array}$ & Authors \& remarks \\
\hline 1. Myrmecia pilosula & 9,10 & $\mathrm{e}$ \\
2. Trigliphothrix walsi & 14 & $\mathrm{~d}$ \\
3. Tapinoma cessile & $(8), 16$ & 1 \\
4. Meranoplus bicolor & 16 & $\mathrm{~d}$ \\
5. Iridomyrmex purpureus group & 18 & $\mathrm{e}$ \\
6. Iridomyrmex sp. 13 ANIC & 18 & $\mathrm{e}$ \\
7. Iridomyrmex gracilis & 18 & $\mathrm{~m}$ \\
8. Polyrhachis sp. 3 (HI82-17) & 20 & $\mathrm{c}$ \\
9. Monomorium sp. 2 ANIC (AAGI-3) & 22 & $\mathrm{e}$ \\
10. Rhytidoponera metallica western from II & 24 & $\mathrm{e}$ \\
11. Myrmecia pilosula (HI85-228) & 24 & Present paper \\
12. Myrmecia pilosula (HI85-379) & 31 & Present paper \\
13. Camponotus sp. 11 ANIC & 32 & $\mathrm{e}$ \\
14. Camponotus sp. 9 nr. variegatus & 34,35 & $\mathrm{~d}$ \\
15. Camponotus sp. 14 ANIC & 38 & $\mathrm{e}$ \\
16. Camponotus consobrinus group sp. 10 ANIC & 46 & $\mathrm{e}$ \\
17. Amblyopone australis cf. fortis & 48 & $\mathrm{e}$ \\
\hline
\end{tabular}

Minor chromosomal mutations: Five cases of partial deletion or duplication are known (Table 7). All are derived secondarily from non-disjunction in translocation heterozygotes. These cases include one each of monosomy (Myrmecia) and trisomy (Pachycondyla). These numerical mutations seem to be more persistent in ants than in other animals, as mentioned above. They are, however, exceptional even in these insects, and have probably contributed little to ant karyotype evolution. Supernumerary chromosomes have been recorded in Leptothorax, Podomyrma, Pseudolasius and Prenolepis (Table 7). Because of the existence of doubled chromosome numbers in related species karyotype evolution by polyploidization has been suggested (Imai, 1969; Crozier, 1975). Hauschteck 
Table 7. Minor chromosomal mutations in ants

\begin{tabular}{|c|c|c|}
\hline Taxon (code no.) & $\begin{array}{l}\text { Chrom. no. } \\
\text { (n) 2n }\end{array}$ & Authors \& remarks \\
\hline \multicolumn{3}{|c|}{ Pseudo-acrocentries $\left(\mathrm{A}^{\mathrm{M}}\right)$ : Fluctuation of heterochromatic short arms by t.g.c.h. and e.c.h. } \\
\hline 1. Myrmecia (pilosula) (HI85-379) & 31,32 & Present paper \\
\hline 2. Vollenhovia sp. 3 ANIC & 40 & e \\
\hline 3. Podomyrma adelaidae & 50,51 & e \\
\hline 4. Bothroponera sp. $2=$ Pachycondyla & 60 & e \\
\hline 5. Myrmecia brevinoda & 84 & e \\
\hline \multicolumn{3}{|l|}{ Partial deletion or duplication } \\
\hline 1. Myrmecia (pilosula) (AAGT-11) & 9,10 & e \\
\hline 2. Monomorium indicum & 21,22 & $\mathrm{~d}$ \\
\hline 3. Camponotus sp. 9 nr. variegatus & 34,35 & d \\
\hline 4. Tetramorium sp. 3 (HI78-163, 172) & 35,36 & $d$ \\
\hline 5. Rhytidoponera metallica (Western form II) & 22,23 & e \\
\hline \multicolumn{3}{|l|}{ Supernumerary (B-) chromosomes } \\
\hline 1. Leptothorax spinosior $(\mathrm{n}=12+1 \mathrm{~B} \sim 12 \mathrm{~B})$ & $(12-24)$ & $\mathrm{i}$ \\
\hline 2. Podomyrma adelaidae $(\mathrm{n}=44+6 \mathrm{~B}$ or $7 \mathrm{~B})$ & 50,51 & $\mathbf{e}$ \\
\hline 3. Pseudolasius sp. 2 (HI83-67, 68) & $(15,17,19) 30$ & $\mathrm{~b}$ \\
\hline $\begin{array}{l}\text { 4. Prenolepis jerdoni } \\
(\mathrm{n}=16+4 \mathrm{BI} \sim 11 \mathrm{~B})\end{array}$ & $\begin{array}{l}(16,20,25,27) \\
30,31,32,34\end{array}$ & $\mathrm{~b}$ \\
\hline \multicolumn{3}{|l|}{ Trisomies or monosomies } \\
\hline 1. Myrmecia (pilosula) (HI85-379) & 31,32 & Present peper \\
\hline 2. Pachycondyla astuta (HI84-54), (HI87-3) & 22 & a \\
\hline \multicolumn{3}{|l|}{ Polyploidy } \\
\hline 1. Crematogaster sp. 2 & $3 n=39$ & e \\
\hline 2. Camponotus sp. 5 & $4 n=64$ & e \\
\hline 3. Aphaenogaster osimensis & $\begin{array}{l}(n=16,2 n=32) \\
2 n=32,4 n=64\end{array}$ & j \\
\hline
\end{tabular}

(1965) reported half haploids ( $\mathrm{n} / 2)$ in Myrmica sulcinodis $(\mathrm{n} / 2=14, \mathrm{n}=28$, and $2 n=56$ ). This supposed example must now be abandoned, because the chromosome number of $M$. sulcinodis was shown recently to be $n=24$ (HauschteckJungen and Jungen, 1983). Single tetraploid and triploid mutants have been reported in Crematogaster and Camponotus respectively (Imai et al., 1977), and polyploid cells appear frequently in Aphaenogaster preparations (Imai and Yosida, 1966). Despite these observations, solid evidence for the existence of polyploid species has not been provided by extensive chromosome surveys of Imai and associates. On the contrary, indirect data suggests constancy of genome size in ants, such that the absolute size of individual chromosomes decreases as chromosome number increase (Imai et al., 1977).

We have introduced the term 'pseudo-acrocentric' $\left(\mathrm{A}^{\mathrm{M}}\right)$ in discussing fluctuation of heterochromatic short arms. Pseudo-acrocentrics are defined above as 'acrocentries with extraordinarily elongated heterochromatic short arms'. They 
would conventionally be classified as M, SM, or ST chromosomes. Myrmecia brevinoda $(2 n=84)$ provides a typical example. Here all chromosomes are $\mathrm{A}^{\mathrm{M}_{\mathrm{S}}}$ (Imai et al., 1977). Another, in Myrmecia (pilosula), is discussed above (Figs 8 and 9), which indicates that $A^{M}$ chromosomes are induced very rapidly from telocentrics (T) via acrocentrics (A), by tandem growth of constitutive heterochromatin (t.g.c.h.; Fig. 10c). Pseudo-acrocentrics, though exceptional (Table 7), are found also in mammals, including Peromyscus (Baker et al., 1987; Stangle and Baker, 1984). This case suggests that $A^{M}$ chromosomes are intermediate products of chromosomal alteration from acrocentric to metacentric, by pericentric inversion $\left(A \rightarrow A^{M} \rightarrow \bar{M}\right) . \quad A^{M} \rightarrow \bar{M}$ alterations occur also in ants through a special type of centric fusion, which is termed 'dicentric fusion' or 'telomere fusion' (Fig. 10a) in the discussion to follow.

In summary: (1) Robertsonian rearrangement, pericentric inversion, and translocation are the most important modes of spontaneous chromosomal mutation in ants; (2) translocations and Robertsonian polymorphisms are non-randomly distributed, the former in chromosomally low-numbered species $(n \leq 12)$, and the latter in those with high numbers $(>12)$; and (3) heterochromatic short arms of acrocentrics may become extraordinarily elongate in some karyotypes, and in these centric fusions tend to appear frequently. Any hypothesis relating to karyotype evolution in ants must be consistent with these observations.

\section{2) The minimum interaction hypothesis in ant karyotype evolution}

The minimum interaction hypothesis of Imai et al. (1986) proposes that spontaneous chromosomal mutation follows a two-step process, involving (1) physical proximity of DNA strands under the suspension arch structure at pachytene (called here the hammock structure to ease visualization), and (2) successive exchange between these strands by the mis-resolution of inter-locking, and crossing-over. The terms 'suspension arch structure', or 'hammock structure' describe a non-random chromosomal configuration which occurs in pachytene nuclei, and is a result of the attachment of chromosomes to the surrounding nuclear membrane. This structure is universally observed in eukaryotes (e.g., Wettstein et al., 1984).

If the nuclear volume and genome size are held constant, the chances of contact between non-homologous chromosomes in the hammock structure, with a resulting exchange of DNA strands, increases as chromosome number decreases (Imai et al., 1986). As indicated above, translocations appear to be less deleterious in ants than in other animals. However, there is evidence that the majority of ant species have balanced monomorphic karyotypes, and this suggests that (on an evolutionary time-scale) the unbalanced derivatives of translocations cannot persist under selection, even in these insects. If this is the case, the genetic risk due to translocations would be highest in ant species with low chromosome numbers. For this reason, increase in chromosome number by Robertsonian rearrangement 
could be evolutionarily favored in ants, as a process reducing the genetic risks occasioned by translocation.

The minimum interaction hypothesis can satisfactorily explain the non-random distributions of translocations and Robertsonian polymorphisms in ants. Thus, the question of which process predominates-whether fusion or fission-is resolved in favor of fission. Fission is the only available mechanism for increasing chromosome number, and any decrease in chromosome number by centric fusion would increase genetic risk. Centric fusions will occur on occasion, however, and would be positively selected when there is telomere instability.

3) Cyclical alteration of chromosomal morphology and the dynamic stability of ant karyotypes under the minimum interaction hypothesis

Chromosomes may be classified into three groups: $\bar{M}$ (metacentrics, in a broad sense, involving the conventional $\mathrm{M}$, SM, or ST), A (acrocentric), and $\mathrm{T}$ (telocentric). Chromosome morphologies change orthodirectionally in the sequence $\overline{\mathrm{M}} \rightarrow \mathrm{T} \rightarrow \mathrm{A}$, by centric fission and tandem growth of constitutive heterochromatin (t.g.c.h.). According to the minimum interaction hypothesis extreme growth of the heterochromatic short arms of acrocentrics is envisaged as a process of 'struggle' to recover a stable telomere replication system from residual centromeres rendered naked by centric fission. Relevant theoretical discussion of centric fission is provided by Imai et al. (1986) and Imai (1988), and of the molecular genetics of the telomere by Blackburn and Szostak (1984). The heterochromatic short-arms of acrocentrics may sometimes become longer than companion euchromatic arms, as observed in Myrmecia (pilosula) (Fig. 9). These we term pseudo-acrocentrics $\left(\mathrm{A}^{\mathrm{M}}\right)$. The chromosomal mutation accompanied by de novo formation of a centromere observed in Myrmecia (piliventris) $n=3$ (Fig. 6) strongly suggests that the heterochromatic blocks induced by t.g.c.h. can involve multiple centromeres, which are usually dormant or inactive, but which may on occasions be reactivated by appropriate structural rearrangements.

The above scenario is strengthened if the growth of the heterochromatic short arms involves material derived from the centromeric region and including centromeric sequences. Because $\overline{\mathrm{M}}$ s can be derived from $\mathrm{A}$ or $\mathrm{A}^{\mathrm{M}}$ chromosomes by either centric fusion (with a reduction in chromosome number) or by pericentric inversion (with no numerical change), there are two possible cycles inter-relating the $\overline{\mathrm{M}}$ chromosomes with the others. We term these the 'fission-inversion' and 'fission-fusion' cycles (Fig. 12).

Under the minimum interaction hypothesis, the fission-inversion cycle would be the predominant one in ants. This conclusion is reached from consideration of the evolutionary dynamics of karyotypes given the hammock structure. Consider first an all-metacentric karyotype with a low chromosome number (Fig. 12a). This karyotype will have a certain intrinsic genetic risk due to translocations, as discussed above. This risk will be reduced if either the nuclear volume is 

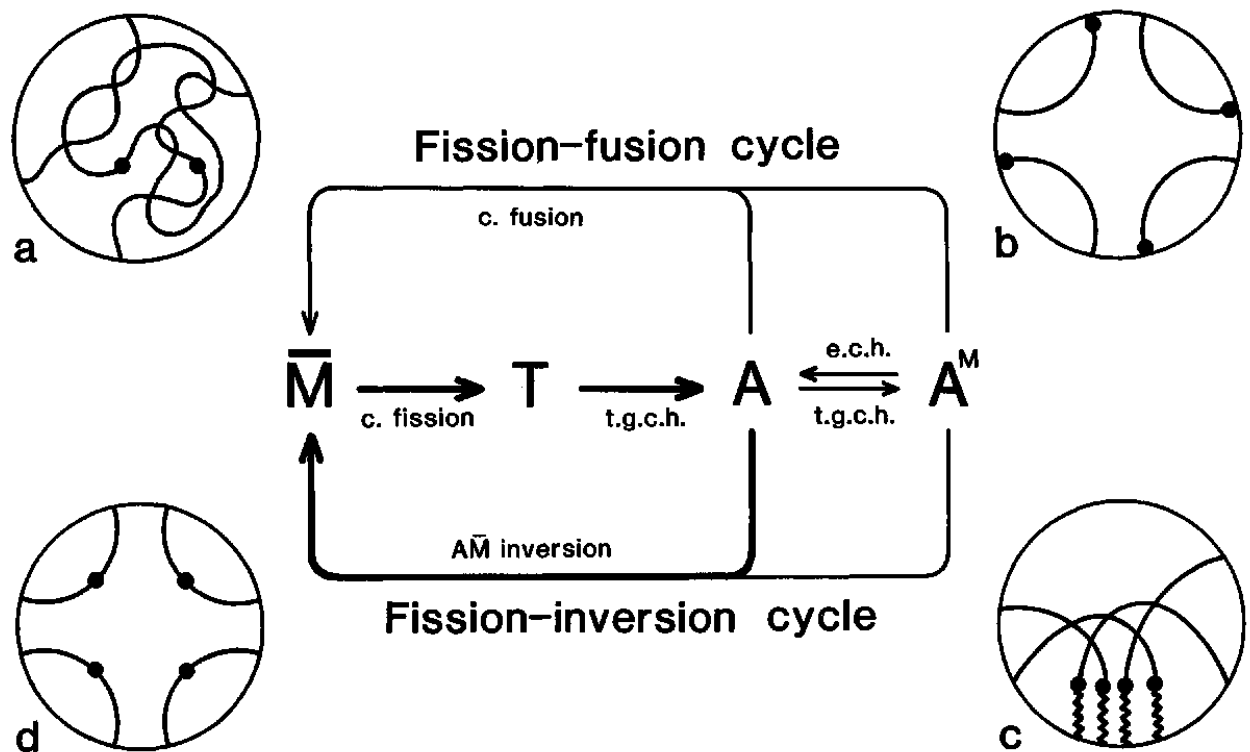

Fission-inversion cycle

Fig. 12 A schematic representation of the cyclical alterations of chromosome morphologies in ants suggested here. $\bar{M}=$ metacentrics (in a broad sense) involving the conventional $M$, SM or ST; e.c.h.= elimination of constitutive heterochromatin; t.g.c.h. =tandem growth of constitutive heterochromatin; $A \bar{M}$ inversion=pericentric inverstion changing $A$ to $\bar{M} ; A^{M}=$ pseudo-acrocentric (which is defined as including acrocentrics with extremely elongated heterochromatic short arms). a. metacentric karyotype with low chromosome number. b. telocentric karyotype. c. acrocentric karyotype. d. metacentric karyotype with high chromosome numbers. The fission-inversion cycle is evolutionarily advantageous for minimizing the genetic risks occasioned by translocation. The fissionfusion cycle is effective as a temporary bypass providing escaping from a non-specific association of heterochromatic short arms in acrocentrics resulting from telomere instability. For details see text.

increased or the chromosome number is increased by centric fission. The end result of repeated fissions would be an all-telocentric karyotype (Fig. 12b). This highernumber has a reduced translocation risk but an increased incidence of telomeric instability following the centric fissions. Selection would therefore favour the rapid gowth of heterochromatic short arms, converting $\mathrm{T}$ chromosomes to $\mathrm{A}$ or $\mathrm{A}^{\mathrm{M}}$ types. Thus, the telocentric karyotype is expected to evolve rapidly by t.g.c.h. into an acrocentric one (Fig. 12c).

Once a karyotype has evolved into an acrocentric one by t.g.c.h., the translocation risk will be increased over that for a telocentric karyotype, because of the tendency of heterochromatin to form non-specific associations. Centric fusion associated with excision of the heterochromatin would reduce these non-specific associations but would be selected against because of the increased translocation risk. Pericentric inversion, accompanied by excision of heterochromatin, will yield a relatively stable karyotype with the new, higher, number (Fig. 12d). Whether this new karyotype remains the same indefinitely will depend on the rate 
of new translocations, which in turn depends on the ratio between mean chromosome length and nuclear volume. If translocation risk remains high, then a new cycle of increasing chromsome numbers will result.

Interpreting our Myrmecia results under the above model, the process of chromosome number increase can clearly be extremely rapid relative to morphological change, because in all three complexes examined morphologically-similar populations display dramatic karyotypic divergence.

Finally, we adduce the non-random distributions of translocations and Robertsonian polymorphisms as evidence in favor of the minimum interaction hypothesis, and conclude that karyotype evolution in ants proceeds generally towards increases rather than decreases in chromosome number, with centric fissions and pericentric inversions being the predominant elements in this process. Occasional centric fusions will also occur, especially in karyotypes possessing pseudo-acrocentrics. We suggest that the models we have developed for ants may be applicable to animals generally, and that they bear on the question of whether chromosome numbers tend more generally to increase or to decrease over evolutionary time.

We thank M. J. Whitten, M. Kubota and K. Masuko for kind assistance in obtaining materials (Myrmecia (pilosula) and Ponera scabra), K. Tokuda for photographic assistance, and The Australian National Parks and Wildlife Service for permission to send an $M$. (pilosula) $n=1$ colony to Japan. This work was supported by the Scientific Visitors Program of the Division of Entomology, CSIRO, Australia (1985; HTI), by a Grant-in-Aid for overseas Scientific Research (No. 62041023) from the Ministry of Education, Japan (HTI), by the Australian Research Grants Scheme (RHC) and by a Rutherford Scholarship (MWJC).

\section{REFERENCES}

BAKER, R. J., QUMSIYEH, M. B. and HoOD, C. S. (1987) Role of chromosomal banding patterns in understanding mammalian evolution. pp. 67-96. In Current mammalogy vol. $1 \mathrm{Ed}$. H H Genoways Plenum Press, New York.

BlackBuRn; E. H. and Szostak, J. W. (1984) The molecular structure of centromeres and telomeres. Ann Rev. Biochem. 53: 163-194.

BRown, W. L. Jr. (1953) Revisionary notes on the ant genus Myrmecia of Australia. Bull. Mus. comp. Zool. Harv. III: 1-35.

ClARK, J. (1954) The Formicidae of Australia. Vol. 1. Subfamily Myrmeciinae. Melbourne. CSIRO $230 \mathrm{pp}$.

Crosland, M. W. J and Crozier, R. H. (1986) Myrmecia pilosula, an ant with only one pair of chromosomes. Science 231: 1278.

Crosland, M. W. J., Crozier, R. H. and ImaI, H. T. (1988) Evidence for several sibling biological species centred on Myrmecia pilosula (F. Smith) (Hymenoptera: Formicidae). J. Aust. Ent. Soc. 27: 13-14.

CRow, J. F. and Krmura, M. (1970) An introduction to population genetics theory. Harper \& Row, Publishers, New York.

CrozIER, R. H. (1968) Cytotaxonomic studies on some Australian dolichoderine ants (Hymenoptera: Formicidae). Can. J. Genet. Cytol. 12: 541-546. 
Crozier, R. H. (1969) Chromosome number polymorphism in an Australian ponerine ant. Can. J. Genet. Cytol. 11: 333-339.

CRozIER, R. H. (1970) Pericentric rearrangement polymorphism in a North American dolichoderine ant (Hymenoptera: Formicidae). Can. J. Genet. Cytol. 12: 541-546.

Crozier, R. H. (1975) Hymenoptera. Animal cytogenetics. Vol. 3. Insecta 7. Berlin, Stuttgart: Gebrüder Borntrager.

Goñi, B., Imai, H. T., Kubota, M., Kondo, M., Yong, H. S. and Tho, Y. P. (1982) Chromosome observations of tropical ants in Western Malaysia and Singapore. Ann. Rep. Natl. Inst. Genet. (Jpn) 32: 71-83.

HaUSCHTECK, E. (1965) Halbe haploidie Chromosomenzahl in Hoben von Myrmica sulcinodis Nyl. (Formicidae). Experientia 21: 323-325.

Hauschteck, -Jungen, E. and Jungen, H. (1983) Ant chromosomes. II. Karyotypes of western palearctic species. Insectes Sociaux Paris 30: 149-164.

Hirai, H., Sakaguchi, Y. and Imai, H. T. (1981) C-band polymorphism in a Japanese lung fluke Paragonimus ohirai (Trematoda; Platyhelminthes). Heredity 47: 249-252.

Imai, H. T. (1969) Karyological studies of Japanese ants I. Chromosome evolution and species differentiation in ants. Sei. Rep. Tokyo Kyoiku Daigaku, B. 14: 27-46.

ImaI, H. T. (1974) B-chromosomes in the myrmicine ant, Leptothorax spinosior. Chromosoma (Berl.) 45: 431-444.

IMAI, H. T. (1986) Modes of species differentiation and karyotype alteration in ants and mammals. In Modern aspect of species. pp. 87-105. Ed. Iwatsuki, K., Raven, P. H., Bock, W. J. Univ. of Tokyo Press, Tokyo.

ImaI, H. T. (1988) Centric fission in man and other mammals. In Cytogenetics of mammalian autosomal rearrangements. Ed. Daniel, A., Alan, R. Liss, New York, (In press).

Imai, H. T., Baroni-urbani, C. Kubota, M., Sharma, G. P., Narashimhanna, M. N., Das, D. C., SharMa, A. K., Sharma, A., Deodikar, G. B., Vaidya, V. G. and Rajasekarasetty, M. R. (1984a) Karyological survey of Indian ants. Jpn. J. Genet. 59: 1-32.

Imai, H. T., Brown, W. L. Jr., Kubota, M., Yong, H. S. and Tho, Y. P. (1984b) Chromosome observations of tropical ants in western Malaysia (2). Ann. Rep. Natl. Inst. Genet. (Jpn) 34: 6669.

Imai, H. T., Crozier, R. H. and TAYLoR, R. W. (1977) Karyotype evolution in Australian ants. Chromosoma (Berl.) 59: 341-393.

Imai, H. T. and KuBOTA, M. (1972) Karyological studies of Japanese ants, (Hymenoptera: Formicidae). III. Chromosoma (Berl.) 37: 193-200.

Imai, H. T. and Kuвota, M. (1975) Chromosome polymorphism in the ant, Pheidole nodus. Chromosoma (Berl.) 51: 391-399.

Imai, H. T., Kubota, M., Brown, W. L. Jr., Ihara, M., Tohari, M. and Pranata, R. I. (1985) Chromosome observations on tropical ants from Indonesia. Ann. Rep. Natl. Inst. Genet. (Jpn) 35: 46-48.

Imai, H. T., Maruyama, T., Gojobori, T., Inoue, Y. and Crozier, R. H. (1986) Theoretical bases for karyotype evolution. 1. The minimum interaction hypothesis. Am. Nat. 128: 900-920.

IMAI, H. T. and TAYLOR, R. W. (1986) The exceptionally low chromosome number $\mathbf{n}=2$ in an Australian bulldog ant, Myrmecia piliventris Smith (Hymenoptera: Formicidae). Ann. Rep. Natl. Inst. Genet. (Jpn). 36:59-61.

ImaI, H. T. and Yosida, T. H. (1966) Polyploid cells observed in male and queen ants of Aphaenogaster osimensis. Ann. Rep. Natl. Inst. Genet. (Jpn) 16: 54.

Matsuda, M., Imai, H. T. and ToBari, Y. N. (1983) Cytogenetic analysis of recombination in males of Drosophila ananassae chromosoma (Berl.) 88: 286-292.

Stangle, F. B. Jr. and Baker, R. J. (1984) Evolutionary relationships in Peromyscus: Congruence 
in chromosomal, genic, and classical data sets. J. Mammal. 65: 643-654.

TAYLoR, R. W. (1975) Nothomyrmecia macrops: a living-fossil ant rediscovered. Science N. Y. 201: 979-985.

TAYLOR, R. W. (1987) A checklist of the ants of Australia, New Caledonia and New Zealand (Hymenoptera: Formicidae). CSIRO Aust. Div. Entomol. Rep. 41: 1-92.

von Wertstein, D., Rasmussen, S. W. and Holm, P. B. (1984) The synaptonemal complex in genetic segregation. Ann. Rev. Genet. 18: 331-413.

White, M. J. D. (1973) Animal cytology and evolution. 3d eds. Cambridge University Press, London. Wilson, E. C. (1971) The insect societies. Belknap Press Harvard, Cambridge.

WRIGHT, S. (1941) On the probability of fixation of reciprocal translocations. Am. Nat. 75: 513-522. 